\title{
Alarmieren
}

Für die Bewältigung einer nuklearen Katastrophe - verursacht durch eine Atombombe oder einen Reaktorunfall - kam einem raschen und effizienten Strahlenalarm eine zentrale Bedeutung zu. Ohne rechtzeitige und koordinierte Alarmierung drohte jede noch so sorgfältig geplante Schutzmaßnahme, so insbesondere ein möglicher Schutzraumbezug, entscheidend an Wirksamkeit zu verlieren. Ein funktionierendes Alarmierungsdispositiv bildete deshalb eine konstitutive Voraussetzung der gouvernementalen Vorbereitung auf eine Atomkatastrophe. Die gesamte Vorbereitung wiederum verfolgte den Zweck, im Hinblick auf ein allfälliges nukleares Katastrophenereignis eine permanente preparedness herzustellen. Die Ursprünge des Konzeptes der preparedness liegen im frühen Kalten Krieg, als die Möglichkeit eines Atomkrieges zur neuen Leitbedrohung avancierte. ${ }^{1}$ Preparedness - so der Soziologe Ulrich Bröckling - zielt darauf ab, einen „Aufschub zu erlangen“ und ist insofern „darauf beschränkt, dem Unvermeidlichen entgegenzusehen und bestenfalls den erwarteten Schaden in Grenzen zu halten. ${ }^{2}$ Preparedness wird zumeist auf nationale Sicherheit bezogen und meint in diesem Zusammenhang einen Rationalitätstypus, der auf Gefahren und Risiken mit zwar nur geringer Eintretenswahrscheinlichkeit, aber potenziell katastrophalen Folgen ausgerichtet ist. ${ }^{3}$

Die in diesem Kapitel im Zentrum stehende Alarmorganisation sowie deren Alarmzentralen und Alarmsysteme lassen sich als Materialisierung der in der Schweiz des Kalten Krieges vorherrschenden preparedness für atomare Notfälle beschreiben. Diese preparedness setzte dabei nicht mit dem heute noch bekannten Ertönen der Sirenen ein. Das Sirenengeheul markierte nicht den Beginn einer nuklearen Katastrophe, es fungierte vielmehr als hörbares Zeichen eines erfolgreichen Alarmierungsprozesses. Damit dieser Prozess funktionierte, mussten eine Vielzahl von Personen und Institutionen, Infrastrukturen und Ressourcen in die Alarmorganisation eingebunden werden. Die Alarmorganisation setzte deshalb - so wird sich zeigen - enorme Koordinationsanforderungen voraus und ihr Auf- und Ausbau war wesentlich von politischen Faktoren und Kontexten geprägt. Wie war der Strahlenalarm

1 Vgl. Collier/Lakoff 2008a; Collier/Lakoff 2008b.

2 Bröckling 2012, S. 103.

3 Vgl. Kaufmann 2011, S. 103 f.

(C) SIBYLLE MARTI, 2021 | DOI:10.30965/9783657704439_007

This is an open access chapter distributed under the terms of the CC BY-NC-ND 4.o license. Marti - 9783657704439 
in der Schweiz während des Kalten Krieges institutionell organisiert, wie sollte er praktisch funktionieren und gegen welche atomaren Bedrohungen richtete sich das Alarmierungsdispositiv?

\subsection{Doppelspurigkeiten und Koordinationslücken. Institutionalisierung des Alarmausschusses für den Fall erhöhter Radioaktivität, 1962-1984}

Der Strahlenalarm stellte eine Aufgabe dar, mit dem sich seit den 195oer Jahren verschiedene zivile und militärische Stellen befassten. Je nachdem, ob eine allfällige Atomkatastrophe im Friedens- oder im Kriegszustand stattfinden würde, ergaben sich für diese Stellen unterschiedliche Herausforderungen. Die Eidgenössische Kommission zur Überwachung der Radioaktivität (KUeR) war laut ihrem Reglement bei gefährlich erhöhter Radioaktivität dafür verantwortlich, dem Bundesrat Maßnahmen zum Schutz der Bevölkerung vorzuschlagen. ${ }^{4}$ Bei einem Nuklearereignis, das in Kriegszeiten stattfinden würde, stellte sich für die KUeR als zivile Behörde allerdings das Problem, dass ihre Mitglieder und die von ihr angestellten Physiker und Chemiker im Fall einer Mobilmachung in ihre Armeeeinheiten einzurücken hatten. „Das Ueberwachungsnetz der Kommission würde dadurch“ - so die Befürchtung der KUeR - "gerade im wichtigsten Moment stillgelegt." ${ }^{5}$ Die Aufrechterhaltung der Alarmierung im Aktivdienst- und Kriegsfall bedurfte folglich einer Lösung. Dies umso mehr, weil der Territorialdienst und die Luftschutztruppen der Armee nach einer Mobilmachung selbst einen Atomwarndienst betreiben und bei den Truppen die Spezialisten der Sektion für Schutz und Abwehrmaßnahmen gegen ABC-Waffen der Abteilung für Sanität des Eidgenössischen Militärdepartements (EMD) zum Einsatz kommen würden. ${ }^{6}$ Obwohl die Aufgaben dieser militärischen Stellen und diejenigen der KUeR nicht deckungsgleich waren, sondern sich vielmehr ergänzen sollten, sei es wie die KUeR betonte - „notwendig, dass [...] die Arbeit dieser verschiedenen Stellen für den Fall des Aktiv- und Kriegsdienstes koordiniert werden [...]."7

Doch auch hinsichtlich einer Atomkatastrophe, die sich zu Friedenszeiten ereignen würde, bestand Kooperationsbedarf. So konnte weder die KUeR

4 Vgl. Archiv BAG, 18.1.1.26, Bundesratsbeschluss, Alarmorganisation vom 24.2.64, Antrag des EDI, 13.12.1963. Vgl. zur KUeR auch Kapitel 3.

5 CH-BAR\#E819oB-o1\#1986/181\#130*, Protokoll der 8. Sitzung der KUeR, 19.12.1957.

6 Vgl. ebd.

7 Ebd. 
noch das Eidgenössische Gesundheitsamt (EGA), welchem die KUeR in der Verwaltung administrativ angegliedert war, auf genügend Material und Fachpersonal zurückgreifen, um bei einem nuklearen Ereignis die notwendigen Schutzmaßnahmen ergreifen zu können. Demgegenüber verfügte die ABCSektion der Abteilung für Sanität sowohl über ausgebildetes Personal als auch über die notwendigen Instrumente. Es sei daher "sinnvoll“ - so hielten die Mitglieder der KUeR in Übereinstimmung mit Militärvertretern fest -, den ABC-Dienst der Armee auch bei einem Katastrophenfall in Friedenszeiten einzusetzen. ${ }^{8}$ Für einen effizienten Atomalarm und einen wirksamen Strahlenschutz war eine koordinierte Zusammenarbeit zwischen der KUeR und verschiedenen militärischen Stellen, insbesondere der ABC-Sektion der Abteilung für Sanität, folglich unerlässlich.

Bis sich die verschiedenen zivilen und militärischen Stellen auf Bundesebene auf die dafür erforderlichen rechtlichen und institutionellen Strukturen verständigen konnten, sollte es indessen etliche Jahre dauern: Es wird sich in diesem Teilkapitel zeigen, dass die Einbindung und Verankerung einer funktionierenden Organisation für den Strahlenalarm innerhalb des schweizerischen Gesamtverteidigungssystems eine nicht abreißende Geschichte von Doppelspurigkeiten und Koordinationslücken darstellte. Das Grundproblem, mit denselben Institutionen, demselben Personal und denselben Geräten Strukturen zu schaffen, die sowohl für den Friedens- als auch für den Aktivdienst- bzw. Kriegsfall tauglich waren, bildete dabei eine dauernde Herausforderung. Die für die Schweiz im Kalten Krieg besonders prägende Verschränkung von zivilen und militärischen Ressourcen und Handlungslogiken führte zu komplizierten institutionellen Strukturen und anhaltenden Koordinationsproblemen, die - so wird deutlich werden - auf eine strukturelle Schwäche des schweizerischen Gesamtverteidigungssystems verweisen.

\section{Militärische Kehrtwenden}

Anfang der 196oer Jahre schien die Schaffung einer Alarmorganisation für den Fall erhöhter Radioaktivität zunehmend dringlicher. So hielt der Präsident der KUeR Paul Huber anlässlich einer Sitzung im Mai 1961 fest, der Bundesrat müsse darauf aufmerksam gemacht werden, dass momentan für Atomkatastrophen, die zu Friedenszeiten stattfinden würden, „überhaupt nichts vorbereitet ist“.9 Diese Einschätzung teilten der Chef der ABC-Sektion Hermann Gessner und der Chef der Sektion für Strahlenschutz des EGA Gerhart Wagner, die beide regelmäßig als Gäste an den Sitzungen der KUeR

8 Ebd., Protokoll der 11. Sitzung der KUeR, 28.8.1958.

9 Ebd., Protokoll der 23. Sitzung der KUeR, 24.5.1961. 
teilnahmen. ${ }^{10}$ Die KUeR wandte sich deshalb im Juni 1961 mit einem Vorschlag für den Aufbau einer Alarmorganisation an das Eidgenössische Departement des Innern (EDI), der prinzipiell auf Zustimmung stieß. An einer Sitzung mit Vertretern des EMD wurde daraufhin die Frage eines möglichen Einsatzes des ABC-Dienstes der Armee besprochen. ${ }^{11}$ In vorangehenden Besprechungen hatten die Militärangehörigen die Möglichkeit in Aussicht gestellt, bei einem Nuklearereignis im Frieden den ABC-Dienst der Armee aufzubieten. ${ }^{2}$ Nun nahmen die militärischen Stellen von einem Aufgebot der ABC-Truppen Abstand. Sie erklärten sich aber damit einverstanden, der Alarmorganisation ihre Spezialisten in Katastrophenfällen auf freiwilliger Basis zur Verfügung zu stellen. ${ }^{13}$ Nachdem ein Rundschreiben des EGA an die ABC-Offiziere und die A-Spezialisten der Armee bezüglich freiwilliger Mitarbeit „ein günstiges Ergebnis gezeitigt hatte“, erteilte das EDI der KUeR Ende März 1962 den offiziellen Auftrag, „die Organisation nun so rasch wie möglich zu verwirklichen“.14

$\mathrm{Zu}$ diesem Zweck wurde im Juli 1962 eine Subkommission der KUeR gebildet, die sich mit dem Aufbau der Organisation für den Katastrophenfall befassen sollte. Dieser Subkommission gehörten mit Paul Huber, Otto Huber und Paul Ackermann sowohl Mitglieder der KUeR als auch zwei Vertreter der ABCSektion - Sektionschef Hermann Gessner und dessen Stellvertreter - sowie der Chef der Sektion für Strahlenschutz Gerhart Wagner an. ${ }^{15}$ Später kam unter anderem noch Peter Courvoisier vom Eidgenössischen Institut für Reaktorforschung in Würenlingen hinzu. ${ }^{16}$ Bei denjenigen Personen, welche die Entwicklung der Alarmorganisation maßgeblich vorantrieben, handelte es sich also wiederum um Mitglieder des schweizerischen Strahlenschutz-Netzwerkes.

Die Subkommission arbeitete an insgesamt zehn Sitzungen die Grundzüge einer künftigen Alarmorganisation aus. Darauf, wie diese Alarmorganisation praktisch funktionieren sollte, werde ich im nächsten Teilkapitel eingehen. Vorerst geht es mir um die rechtlichen und institutionellen Grundlagen der geplanten Organisation. Diese konnten insbesondere hinsichtlich der Frage, was im Aktivdienstfall mit der Alarmorganisation geschehen sollte, über viele Jahre nicht definitiv festgelegt werden. Grund dafür war hauptsächlich, dass das EMD mehrmals seine Position änderte. Ende der 1950er Jahre hatte

\footnotetext{
10 Vgl. ebd.

11 Vgl. ebd., Protokoll der 26. Sitzung der KUeR, 13.11.1961.

12 Vgl. ebd., Protokoll der 11. Sitzung der KUER, 28.8.1958.

13 Vgl. ebd., Protokoll der 26. Sitzung der KUeR, 13.11.1961.

14 Ebd., Protokoll der 29. Sitzung der KUeR, 7.6.1962.

15 Vgl. ebd.

16 Vgl. Archiv BAG, 18.1.1.26, Bundesratsbeschluss, Alarmorganisation vom 24.2.64, Schreiben von P. Huber an H. P. Tschudi, 12.8.1963.
} 
es noch die Meinung vertreten, im Aktivdienst- und Kriegsfall sei der Atomschutz Sache der Armee. Zu Beginn der 196oer Jahre stellte es sich auf den Standpunkt, die Alarmorganisation solle sowohl in Friedenszeiten als auch in Zeiten aktiven Dienstes einen zivilen Charakter aufweisen, ihr könne jedoch militärisches Material zur Verfügung gestellt werden, soweit die militärische Bereitschaft dadurch nicht in Mitleidenschaft gezogen werde. ${ }^{17}$ Demgegenüber war in der Verordnung über den Territorialdienst der Armee festgelegt, dass dieser im Aktivdienstfall die Warnung der Bevölkerung übernehme. Damit vertrat das EMD, was den Strahlenalarm im Mobilmachungs- oder Kriegsfall anbelangte, eine inkonsistente Haltung. Es ist deshalb wenig erstaunlich, dass die Frage der Organisation und der Koordination bei einer Mobilmachung in der Subkommission auch nach über einem Jahr immer noch eine - wie ein Sitzungsprotokoll festhielt - "grosse Diskussion“ auslöste. ${ }^{18}$

Bevor für dieses Problem eine Lösung gefunden war, wurde am 17. Februar 1964 per Bundesratsbeschluss die Alarmorganisation für den Fall erhöhter Radioaktivität offiziell ins Leben gerufen und als deren leitendes Organ der sogenannte Alarmausschuss der KUeR bezeichnet. ${ }^{19}$ Dieser Alarmausschuss der von KUeR-Präsident Paul Huber in Personalunion geleitet wurde - umfasste dreizehn Mitglieder, zu welchen neben den ehemaligen Mitgliedern der Subkommission nun auch Vertreter aller am Problem der Radioaktivität interessierten Departemente sowie der Direktor des neu geschaffenen Bundesamtes für Zivilschutz zählten. ${ }^{20}$ In seinem Antrag an den Bundesrat betonte das EDI, es sei „unbestritten“, dass in der zu schaffenden Alarmorganisation „alle verfügbaren Mittel sinnvoll einzusetzen“ seien. ${ }^{21}$ So habe die Landesverteidigungsübung des Jahres 1963, anlässlich welcher die Bewältigung einer Verstrahlungslage geprobt wurde, „besonders deutlich“ gezeigt, dass sich die Regelung der Zusammenarbeit von zivilen und militärischen Strahlenschutzstellen im Aktivdienstfall „als dringlich“ erweise. ${ }^{22} \mathrm{Zu}$ diesem Zweck müsse

\footnotetext{
17 Vgl. ebd., Antrag des EDI, 13.12.1963.

18 CH-BAR\#E2Oo1E\#1978/84\#1013*, Protokoll der 9. Sitzung der Subkommission, 14.10.1963.

19 Vgl. Archiv BAG, 18.1.1.26, Bundesratsbeschluss, Alarmorganisation vom 24.2.64, Beschluss des Bundesrates, 17.2.1964.

20 Vgl. ebd., Verfügung des EDI über die Ernennung der Mitglieder des leitenden Organs („Alarmausschuss“) der Alarmorganisation für den Fall erhöhter Radioaktivität, 24.2.1964.

21 Ebd., Antrag des EDI, 13.12.1963.

22 Vgl. dazu auch Kapitel 5.1.
} 
„möglichst bald“ eine Verordnung erlassen werden, „die die Aufgaben der Organisation, ihren Aufbau und ihre Arbeitsweise im Einzelnen regeln soll. “23

Am 15. Oktober 1966 setzte der Bundesrat eine derartige Verordnung in Kraft. ${ }^{24}$ Dadurch erfolgte zwar eine Offizialisierung der bereits erwähnten Freiwilligenorganisation, die aus ABC-Spezialisten der Armee bestehen und bei Nuklearereignissen in Friedenszeiten zum Einsatz kommen sollte. Die Frage der Koordination im Aktivdienstfall hingegen wurde in der Verordnung lediglich aufgeworfen, jedoch nicht geregelt. Wiederum lag der Grund dafür in einer Kehrtwendung des EMD. Das Militär wollte nun nichts mehr davon wissen, dass die Alarmorganisation in jedem Fall über einen zivilen Charakter verfügen sollte. Vielmehr plädierte es nun dafür, dass „für den aktiven Dienst [...] eine besondere Regelung getroffen werden“ müsse. ${ }^{25}$ Die institutionelle und rechtliche Einbindung von Alarmorganisation und Alarmausschuss in die Struktur der schweizerischen Landesverteidigung wurde damit bis auf Weiteres vertagt.

Gegen Ende der 196oer Jahre wurde das Problem der Organisation von Strahlenalarm und Strahlenschutz im Mobilmachungs- und Kriegsfall erneut virulent. Wesentlich war hier die Landesverteidigungsübung des Jahres 1967, anlässlich welcher wiederum gravierende Koordinationsdefizite in diesem Bereich zutage traten. ${ }^{26} \mathrm{Im}$ EGA ärgerte man sich darüber, dass das Militär keinerlei Anstalten machte, das seit langem bekannte Problem anzugehen. So hielt der neue Chef der Sektion für Strahlenschutz (und Nachfolger von Gerhart Wagner) Walter Minder in einer internen Notiz an EGA-Direktor Arnold Sauter sichtlich frustriert fest:

Trotz mehrmaligen Bemerkungen bei Sitzungen an den Chef der AC-Sektion und anlässlich der Berichterstattung über die Landesverteidigungsübung 1967, dass es nun Sache des EMD sei, für den Fall des Aktivdienstes eine Unterstellung und Verwendung des Alarmausschusses auszuarbeiten, ist bisher in dieser Sache leider nichts Konkretes vorgenommen worden. ${ }^{27}$

23 Archiv BAG, 18.1.1.26, Bundesratsbeschluss, Alarmorganisation vom 24.2.64, Antrag des EDI, 13.12.1963.

24 Vgl. Archiv BAG, 18.10.57a, Arbeitsgruppe „Alarmzentrale“, Beschluss des Bundesrates, 9.9.1966.

25 Ebd., Mitbericht des EMD, 10.3.1965.

26 Vgl. dazu auch Kapitel 5.1.

27 Archiv BAG, 18.10.57, Alarmorganisation für den Fall erhöhter Radioaktivität, Notiz von W. Minder an Direktor Sauter, 1.10.1968. Vgl. auch ebd., Schreiben von Sauter an die Direktion der Eidg. Militärverwaltung, 12.11.1968. 
Auch seitens des Alarmausschusses führte die jahrelange unklare rechtliche und institutionelle Einbindung im Aktivdienstfall zunehmend zu Unmut. Der Präsident des Alarmausschusses Paul Huber wandte sich deshalb Ende 1970 mit einem Schreiben direkt an den Vorsteher des EDI, Bundesrat Hans-Peter Tschudi. Darin betonte Huber, „dass es nach der jetzigen Konzeption dem A-Ausschuss [Alarmausschuss] unmöglich ist, alle Aspekte einer Katastrophensituation bei gefährlich erhöhter Radioaktivität zu bewältigen. ${ }^{28}$

Die Voten von Walter Minder und Paul Huber weisen darauf hin, dass die Alarmorganisation zu Beginn der 197oer Jahre rechtlich und materiell nach wie vor auf wackligen Füßen stand. Im Prinzip bestanden immer noch die gleichen Organisations-, Kompetenz- und Koordinationsprobleme wie zum Zeitpunkt der Bildung der Subkommission für die Organisation des Katastrophenfalls im Sommer 1962. Auf Bundesebene befassten sich inzwischen allerdings bereits vier verschiedene zivile und militärische Instanzen mit der Bewältigung von Nuklearkatastrophen: Zu den drei bereits erwähnten Stellen - dem Alarmausschuss der KUeR, der Territorialorganisation der Armee und der Unterabteilung AC-Schutzdienst der Abteilung für Sanität - kam seit 1963 noch das Bundesamt für Zivilschutz hinzu. ${ }^{29}$ Die Koordination von Atomalarm und Strahlenschutz war somit mehr denn je vonnöten.

Dieser Koordinationsaufgabe nahm sich nun die 1970 im Rahmen der Leitungsorganisation des Bundes im Bereich der Gesamtverteidigung neu geschaffene Zentralstelle für Gesamtverteidigung (ZGV) an. ${ }^{30}$ ZGV-Direktor Hermann Wanner stellte Ende 1970 in einem Schreiben an Bundesrat Tschudi fest, hinsichtlich der Alarmierung und des Schutzes der Bevölkerung bei einer Nuklearkatastrophe habe sich "ein Mangel an Koordination deutlich gezeigt“. Ebenso sei klar geworden - so Wanner weiter -, „dass es sich hier um ein Problem der Gesamtverteidigung handelt. Es wäre deshalb wünschenswert, [...] das Problem in seiner Gesamtheit neu zu überdenken. ${ }^{\text {31 }}$ Die Suche nach einer effektiven Organisation für den Strahlenalarm und Atomschutz ging damit zu Beginn der 1970er Jahre unter dem neuen Anspruch der Gesamtverteidigung in die nächste Runde.

Resümiert man die ersten zehn Jahre, in welchen auf Bundesebene die Entwicklung einer Alarmorganisation für den Fall erhöhter Radioaktivität angestrebt wurde, so fallen insbesondere zwei Punkte auf: Der erste Punkt

28 Ebd., Schreiben von P. Huber an H. P. Tschudi, 6.11.1970.

29 Vgl. ebd., Schreiben von H. Wanner an H. Tschudi, 22.12.1970.

30 Zur Leitungsorganisation des Bundes im Bereich der Gesamtverteidigung vgl. Kapitel 5.2.

31 Archiv BAG, 18.10.57, Alarmorganisation für den Fall erhöhter Radioaktivität, Schreiben von H. Wanner an H. Tschudi, 22.12.1970. 
betrifft die enge Verschränkung von zivilen und militärischen Strukturen. Im Hinblick auf die Bewältigung einer Atomkatastrophe, die zu Friedenszeiten stattfinden würde, wurde eine Alarmorganisation mit ziviler Leitung - dem Alarmausschuss der KUeR - aufgebaut. Bei einem nuklearen Notfall sollte diese Alarmorganisation mit ungefähr 300 freiwillig tätigen Offizieren, Unteroffizieren und Soldaten des ABC-Dienstes der Armee und mit militärischem Material operieren. Die Zeughäuser [Arsenale] erhielten zu diesem Zweck eine spezielle Weisung der Kriegsmaterialverwaltung, dass sie diesen Freiwilligen in einem Katastrophenfall ABC-Material der Armee zur Verfügung zu stellen hätten. Wiewohl sich ein allfälliger Einsatz nicht auf ein militärisches Aufgebot, sondern auf ein freiwilliges Commitment der entsprechenden Personen stützen würde, sollte die Mobilisierung dieser ABC-Spezialisten - wie im militärischen Kontext - durch die ABC-Sektion der Abteilung für Sanität und nicht direkt durch den Alarmausschuss erfolgen. ${ }^{32}$ Dies verdeutlicht, wie stark militärische und zivile Ressourcen und Organisationsformen im Dispositiv der Alarmorganisation ineinander verwoben waren - dies allerdings vorerst nur für atomare Notfälle in Friedenszeiten.

Zweitens wurde - obwohl von Beginn an als Problem erkannt - die Frage nach der rechtlichen und institutionellen Einbindung und Unterstellung des Alarmausschusses und der Alarmorganisation während eines Aktivdienstes nie beantwortet, sondern eine Lösung vielmehr permanent aufgeschoben. Dies ist insofern erstaunlich, als die Landesverteidigungsübungen der 196oer Jahre mit aller Deutlichkeit gezeigt hatten, dass eine bessere Koordination der im Bereich von Atomalarm und Strahlenschutz bestehenden zivilen und militärischen Stellen im Mobilmachungs- bzw. Kriegsfall dringend erforderlich war. Wesentlich verantwortlich dafür, dass keine Regelung gefunden werden konnte, war die unentschiedene Haltung des EMD. Entgegen seiner ursprünglichen Intention wollte das Militär seine Kompetenzen und sein Know-how in Sachen Strahlenalarm und Atomschutz im Aktivdienstfall schließlich doch nicht aus der Hand geben. Dies hatte - wie der nächste Abschnitt zeigen wird nicht zuletzt damit zu tun, dass das Militär Schwierigkeiten hatte, diejenigen Koordinationsanforderungen, die mit der Konzeption der Gesamtverteidigung einhergingen, zu erfüllen.

32 Vgl. Archiv BAG, 18.1.1.26, Bundesratsbeschluss, Alarmorganisation vom 24.2.64, Schreiben des EDI an das Eidg. Politische Departement, das Eidg. Justiz- und Polizeidepartement, das EMD, das Eidg. Volkswirtschaftsdepartement und das EVED, [10.9.1963]. In manchen Archivdokumenten ist von nur 200 Freiwilligen die Rede. 


\section{Mehrfachstudium von Koordinationslücken}

Das Problem der Koordination von Strahlenalarm und Atomschutz wurde Anfang der 197oer Jahre auf Bundesebene gleich mehrfach studiert. So waren nicht weniger als drei Arbeitsgruppen parallel zueinander mit der nuklearen Bedrohung und der Koordination von Strahlenschutzmaßnahmen beschäftigt. Erstens bestand seit 1971 eine Arbeitsgruppe A-Bedrohung. Diese Arbeitsgruppe, nach ihrem Leiter Jean Dübi von der ZGV auch Arbeitsgruppe Dübi genannt, sollte alle Aspekte der atomaren Bedrohung analysieren und Vorschläge für die Festlegung von Verantwortlichkeiten ausarbeiten. ${ }^{33} \mathrm{Zu}$ den Mitgliedern der Arbeitsgruppe Dübi zählten der Präsident des Alarmausschusses (und Bruder des inzwischen verstorbenen Paul Huber) Otto Huber, der Direktor des Bundesamtes für Zivilschutz Walter König sowie Vertreter des Territorialdienstes der Armee und der Unterabteilung AC-Schutzdienst der Abteilung für Sanität, aber auch der neue Chef der Sektion für Strahlenschutz (und Nachfolger von Walter Minder) Werner Hunzinger und der Chef der Sektion für Sicherheitsfragen von Atomanlagen Peter Courvoisier. ${ }^{34}$ Die Arbeitsgruppe Dübi unterstand dem Stab für Gesamtverteidigung, der im Rahmen der Leitungsorganisation des Bundes im Bereich der Gesamtverteidigung die Kooperation zwischen den militärischen und den zivilen Teilen der Verteidigung vorantreiben sollte. ${ }^{35}$

Zweitens existierte eine Arbeitsgruppe Umfassende AC-Schutzmaßnahmen, nach ihrem Vorsitzenden Hans Flückiger, dem Chef der Unterabteilung ACSchutzdienst der Abteilung für Sanität, auch Arbeitsgruppe Flückiger genannt. Diese Arbeitsgruppe war von Oberfeldarzt Reinhold Käser angeregt worden. Seit 1967 gehörte sie einem Unterausschuss des Koordinationsausschusses für zivile und militärische Landesverteidigung, einem Vorläuferorgan des Stabes für Gesamtverteidigung, an. ${ }^{36}$ Auch die Arbeitsgruppe Flückiger sollte die Planung und Koordination von Strahlenschutzmaßnahmen an die Hand nehmen. An der Arbeitsgruppe Flückiger partizipierten unter anderem

33 Vgl. Archiv BAG, 18.10.57, Alarmorganisation für den Fall erhöhter Radioaktivität, Schreiben von H. Wanner an H. Tschudi, 22.12.1970, und Schreiben von Tschudi an H. Wanner, 18.1.1971.

34 Vgl. die entsprechenden Dokumente in: Archiv BAG, 18.6.2, Alarmorganisation, Arbeitsgruppe „A-Bedrohung“ (Dübi).

35 Vgl. Archiv BAG, 18.6.3, Alarmausschuss I. Teil, Protokoll der Informationssitzung über Koordinationsprobleme im Bereiche der A-Bedrohung, 22.10.1971.

36 Vgl. ebd. Es handelte sich dabei um den Unterausschuss Totaler Sanitätsdienst und umfassende AC-Schutzmaßnahmen. Vgl. dazu Kapitel 7.3. 
Vertreter des Alarmausschusses, des Bundesamtes für Zivilschutz und der Territorialorganisation der Armee. ${ }^{37}$

Drittens war seitens des Alarmausschusses seit 1970 eine Arbeitsgruppe Kompetenz- und Organisationsfragen des umfassenden AC-Schutzdienstes tätig. Diese Arbeitsgruppe, die unter der Leitung von Paul Siegenthaler, Chef der Zentralstelle für zivile Kriegsvorbereitung, stand, beschäftigte sich ebenfalls mit Koordinationsproblemen im Bereich von Strahlenalarm und Strahlenschutz. ${ }^{38}$ Der Arbeitsgruppe Siegenthaler gehörten unter anderem Otto Huber, Werner Hunzinger, Walter König, Hans Flückiger, Peter Courvoisier sowie ein Vertreter des Territorialdienstes der Armee an. ${ }^{39}$ In den drei parallel zueinander existierenden Arbeitsgruppen, die zu Beginn der 197oer Jahre allesamt die Koordinationslücken im Bereich der nuklearen Bedrohung studierten, waren somit wiederholt identische Personen und Institutionen vertreten. Dieses mehrfache Vorgehen verweist auf ein grundlegendes strukturelles Problem des schweizerischen Gesamtverteidigungssystems, wie sich im Folgenden zeigen wird.

Um die offensichtlich vorhandenen Kooperationsdefizite anzugehen, berief die ZGV im Oktober 1971 eine „Informationssitzung über Koordinationsprobleme im Bereiche der A-Bedrohung“ ein. Zu dieser Sitzung waren Vertreter des Alarmausschusses, des Bundesamtes für Zivilschutz und des ACSchutzdienstes sowie der Oberfeldarzt eingeladen, ebenso die Vorsitzenden der drei parallel zueinander bestehenden Arbeitsgruppen. Deren Situationsanalyse ergab folgendes Bild: Indem der Bundesrat Aufträge an verschiedene Gremien erteilt habe, so an den Alarmausschuss, das Bundesamt für Zivilschutz und den AC-Schutzdienst der Armee, sei es zu „Doppelspurigkeiten und Koordinationslücken“ gekommen. Es handle sich „um ein echtes Koordinationsproblem“, an dessen Lösung verschiedene Departemente - das EDI, das Eidgenössische Justiz- und Polizeidepartement, das EMD und das Eidgenössische Verkehrs- und Energiewirtschaftsdepartement - ein Interesse hätten. Die „Kardinalfrage“ laute: „Wie sollen die verschiedenen für die Erkennung der A-Bedrohung zuständigen Instanzen zu einer im Frieden

\footnotetext{
37 Vgl. Archiv BAG, 18.6.2, Alarmorganisation, Arbeitsgruppe „Umfassender AC-Schutzdienst“ (Flückiger), Der integrierte AC-Schutzdienst, Januar 1972.

38 Vgl. Archiv BAG, 18.6.3, Alarmausschuss I. Teil, Protokoll der Informationssitzung über Koordinationsprobleme im Bereiche der A-Bedrohung, 22.10.1971.

39 Vgl. die entsprechenden Dokumente in: CH-BAR\#E439oC\#1977/164\#355*. Daneben hatte offenbar auch das EGA einen Auftrag, die Fragen der Alarmorganisation im aktiven Dienst zu studieren. Vgl. ebd., Kompetenz- und Organisationsprobleme des umfassenden AC-Schutzdienstes, März 1970.
} 
wie im aktiven Dienst funktionsfähigen Organisation zusammengeschlossen werden?"40

Die Informationssitzung erbrachte ein Resultat. So galt nun als „unbestritten“, dass der Alarmausschuss im Frieden wie bisher funktionieren und dem EDI angehören, im Frieden wie im aktiven Dienst seine Tätigkeit fortführen und im Frieden wie im aktiven Dienst die Koordination im Bereich der atomaren Bedrohung übernehmen sollte. ${ }^{41}$ Damit sollte der Alarmausschuss einerseits als Ausführungsorgan des EDI fungieren, das heißt, im Verstrahlungsfall die vorhandene Radioaktivität messen und beurteilen, Entscheide fällen und Anträge für Schutzmaßnahmen stellen. Andererseits sollte er aber auch als Koordinationsorgan tätig sein und somit auf Bundesebene das Zusammenwirken zwischen den verschiedenen Organen im Bereich der atomaren Bedrohung sicherstellen. Hinsichtlich der Frage der Unterstellung des Alarmausschusses im aktiven Dienst wollten die Sitzungsteilnehmer indessen „nichts präjudizieren“, bis die Berichte der verschiedenen Arbeitsgruppen abgeschlossen seien und vorliegen würden. ${ }^{42}$ Damit wurde die Lösung eines wesentlichen Teils der "Kardinalfrage" erneut aufgeschoben, obwohl das Problem seit Jahren mehrfach studiert wurde. Dieser bewusste Aufschub lag hauptsächlich darin begründet, dass weder die Führungsrolle des Zivilschutzes noch diejenige des Militärs als befriedigende Lösung galten. Zwar wäre seitens der Alarmorganisation eine Unterstellung unter den Zivilschutz favorisiert worden. Der AC-Schutz des Zivilschutzes war jedoch sowohl materiell als auch personell schlechter ausgerüstet als derjenige der Armee und seine Spezialisten zudem weniger gut ausgebildet als diejenigen der Unterabteilung AC-Schutzdienst der Abteilung für Sanität, weshalb diese Möglichkeit nicht als optimal erschien. ${ }^{43}$

Nur wenige Monate nach der Informationssitzung lagen die Berichte der verschiedenen Arbeitsgruppen vor. Die Arbeitsgruppe Dübi bestätigte in ihrem Schlussbericht die Beschlüsse der Informationssitzung. ${ }^{44}$ Demgegenüber ging

40 Archiv BAG, 18.6.3, Alarmausschuss I. Teil, Protokoll der Informationssitzung über Koordinationsprobleme im Bereiche der A-Bedrohung, 22.10.1971, Hervorh. i. Orig.

41 Ebd.

42 Ebd.

43 Vgl. Archiv BAG, 18.10.57a, Alarmzentrale, Der AC-Schutzdienst des Zivilschutzes, 25.8.1970. Das Bundesamt für Zivilschutz verfügte bspw. über keine eigenen Wissenschaftler auf dem Gebiet des AC-Schutzes. Deshalb wurden alle Fachfragen sowie die Ausbildung der Unterabteilung AC-Schutzdienst der Abteilung für Sanität auferlegt. Vgl. Archiv BAG, 18.10.57, Alarmorganisation für den Fall erhöhter Radioaktivität, Schreiben von $\mathrm{H}$. Wanner an H. Tschudi, 22.12.1970.

44 Vgl. Archiv BAG, 18.6.2, Alarmorganisation, Bericht der Studiengruppe betreffend die verschiedenen Aspekte der atomaren Bedrohung, Dezember 1971. 
der Bericht der Arbeitsgruppe Flückiger nur am Rande auf die geforderten Koordinationsleistungen ein, was seitens des Alarmausschusses und des Bundesamtes für Zivilschutz auf Kritik stieß. So meinte der Chef der Sektion für Strahlenschutz Werner Hunzinger, der Bericht sei „einseitig aus dem Blickwinkel der Armee verfasst und vernachlässigt die Schutzbedürftigkeit der Zivilbevölkerung, welche quantitativ überwiegt." Der Vizedirektor des Bundesamtes für Zivilschutz ergänzte, der Bericht lege dar, was die Armee für einen koordinierten AC-Schutzdienst tun könne: „Vor einer Mobilmachung nichts, nach durchgeführter Mobilmachung wenig." Der Präsident des Alarmausschusses Otto Huber wiederum betonte, es dürfe „nicht übersehen werden, dass die Studie einen Widerspruch gegenüber unseren Koordinationsvorstellungen enthält. “45 Diese Aussagen zeigen, dass sich das Militär zu Beginn der 1970er Jahre schwer damit tat, sich auf die Kooperationsgebote der Gesamtverteidigung einzulassen und diesen gerecht zu werden.

Die Vorstellungen im Bericht der Arbeitsgruppe Dübi setzten sich jedoch schließlich durch und bildeten die Basis für die Verordnung über die Koordination der AC-Schutzmaßnahmen, die der Bundesrat im September 1973 erließ.46 Gemäß dieser Verordnung war der Alarmausschuss mit der Koordinationsfunktion im Bereich der nuklearen Bedrohung betraut, indem ein Ausschuss AC-Schutz als ständiges Gremium des Stabes für Gesamtverteidigung geschaffen wurde. Dieser neue Ausschuss AC-Schutz, dessen Vorsitz der Präsident des Alarmausschusses Otto Huber in Personalunion übernahm, war mit dem bestehenden Alarmausschuss praktisch identisch; er wurde lediglich um einige Spezialisten für die chemische Bedrohung ergänzt, die im Alarmausschuss selbstredend nicht vertreten waren. ${ }^{47}$ Beim Ausschuss ACSchutz handelte es sich indessen nur um ein Koordinations- und kein Ausführungsorgan, das heißt, dessen Aufgabe bestand darin, die verschiedenen Ausführungsorgane im Hinblick auf einen künftigen Katastrophen- oder Kriegsfall zu koordinieren. Gleichzeitig blieb der Alarmausschuss in Friedenszeiten weiterhin ein Ausführungsorgan des EDI. Damit wurde die seit längerem im Raum stehende Lösung verwirklicht, den Alarmausschuss sowohl als Ausführungs- als auch - in Form des Ausschusses AC-Schutz - als Koordinationsorgan einzusetzen.

45 Archiv BAG, 18.6.3, Alarmausschuss I. Teil, Aktennotiz über die Sitzung der Arbeitsgruppe des Alarmausschusses betreffend „integrierter AC-Schutzdienst“, 10.3.1972, Hervorh. i. Orig.

46 Vgl. Archiv BAG, 18.2.63, Ausschuss AC-Schutz des Stabes ZGV, Beschluss des Bundesrates, 17.9.1973.

47 Vgl. ebd., Verordnung über die Koordination der AC-Schutzmassnahmen, 17.9.1973. 
Das Problem der Koordination des Atomalarms und des Strahlenschutzes konnte durch die Schaffung des Ausschusses AC-Schutz jedoch nach wie vor nicht befriedigend gelöst werden. So setzte dieser Ende 1973 eine neue Arbeitsgruppe Koordination ein. Die Arbeitsgruppe Koordination sollte sich, wie Otto Huber erläuterte, einen „Ueberblick [...] über den Stand der Arbeiten bei den einzelnen Fachorganen [verschaffen], die sich mit AC Schutzmassnahmen befassen. Diese Bestandesaufnahme soll Ausgangspunkt bilden für die $\mathrm{Zu}$ sammenarbeit in diesem wichtigen Teilbereich der Gesamtverteidigung.“48 Das altbekannte Problem wurde damit zum x-ten Mal von Grund auf studiert. Die Lösung des Koordinationsproblems bestand folglich darin, keine Entscheidungen zu fällen, sondern vielmehr ständig neue Organisationen und Arbeitsgruppen und bisweilen auch neue Regelwerke zu erfinden. Dadurch fand unablässig eine Aufschiebung und Verlagerung des Problems statt.

Auch die Frage, was mit dem Alarmausschuss im Aktivdienstfall passieren solle, wurde mit der Verordnung von 1973 nicht gelöst. So hielt das EMD in seinem Antrag lapidar fest, für den Aktivdienstfall müssten allfällige Aufgaben des Alarmausschusses noch definiert werden. ${ }^{49} \mathrm{Zu}$ einer Klärung kam es erst im Jahr 1976, als der Bundesrat eine Änderung der Verordnung über den Alarmausschuss vornahm. In derselben wurde neu festgelegt, dass die ACSchutzoffiziere und AC-Spezialisten der Armee sowohl im Frieden als auch im Krieg zugunsten des Alarmausschusses zum aktiven Dienst aufgeboten werden könnten. Gleichzeitig sollte der Alarmausschuss nun auch im Aktivdienstfall beim EDI verbleiben. ${ }^{50}$ Das Militär musste sich also letztlich fügen und dem Alarmausschuss Ressourcen in Form von AC-Fachleuten und ACLaboratorien auch im Mobilmachungs- oder Kriegsfall zur Verfügung stellen.

Die Verdoppelung des Alarmausschusses in ein Ausführungs- und ein Koordinationsorgan, die mit der Verordnung über die Koordination der ACSchutzmaßnahmen im Jahr 1973 eingeführt wurde, hatte allerdings nur rund zehn Jahre Bestand. Ende 1984 wurden sowohl der Alarmausschuss der KUeR als auch der mit ihm praktisch identische Ausschuss AC-Schutz des Stabes für Gesamtverteidigung aufgelöst und der Strahlenalarm reorganisiert. Die Aufgaben dieser beiden Ausschüsse gingen an die neu geschaffene Eidgenössische Kommission für AC-Schutz über. ${ }^{51}$ Die Geschichte der institutionellen und rechtlichen Verankerung des Alarmausschusses stellte somit eine

48 Ebd., Schreiben von O. Huber betreffend Erhebung über den Stand der Arbeiten im Bereiche des AC Schutzes zugunsten der Gesamtverteidigung, 27·3.1974.

49 Vgl. ebd., Antrag des EMD, 17.8.1973.

50 Vgl. CH-BAR\#E439oC\#1997/14\#223*, Orientierung über den Koordinierten ACSD, 1.1.1979.

$5^{1} \quad$ Vgl. dazu auch Kapitel 6.2 und Kapitel 8. 
Geschichte der permanenten Verzögerungen und Umwege dar. Sie dauerte über 20 Jahre und bildete ein nie abgeschlossenes Projekt. Mitte der 1980er Jahre wurde der Alarmausschuss umstrukturiert, ohne dass sein Funktionieren je real unter Beweis gestellt worden wäre.

Eine Koordination von Atomalarm und Strahlenschutz wurde zwar während des ganzen Kalten Krieges gefordert, konnte aber nie befriedigend umgesetzt werden. Und dies, obwohl dieselben Personen mit der Konzeption und Ausführung des Strahlenalarms beschäftigt waren, welche auch die Koordinationsprobleme im Bereich der nuklearen Bedrohung studierten und sich seit Anfang der 196oer Jahre regelmäßig, in Arbeitsgruppen und Ausschüssen institutionalisiert, zu Koordinationsbesprechungen zusammenfanden. Dies auf ein Versagen der involvierten Akteure zurückzuführen, ist nicht plausibel. Vielmehr zeigt sich am Beispiel des Alarmausschusses und der Alarmorganisation ein strukturelles Problem des schweizerischen Gesamtverteidigungssystems.

Der während des Kalten Krieges formulierte Anspruch einer permanenten preparedness war nur mittels einer umfassenden nationalen Verteidigung einzulösen, was im Begriff der Gesamtverteidigung zum Ausdruck gelangte. Dadurch dehnte sich das schweizerische Verteidigungssystem aus, was den Beteiligten durchaus bewusst war. So wies etwa EGA-Direktor Arnold Sauter darauf hin, dass das Konzept der Gesamtverteidigung grundsätzlich zu einer Vergrößerung des nationalen Verteidigungsapparats führe. ${ }^{52}$ Für diese Ausweitung stehen die Schaffung des Alarmausschusses und der Aufbau der Alarmorganisation exemplarisch. Ein internes Dokument des Alarmausschusses hielt diesbezüglich fest: „Seit der Gründung der KUeR 1956, der Bestellung des Alarmausschusses 1964, der Uebertragung von Koordinationsaufgaben im AC-Bereich 1973 und der Uebertragung seiner Funktionen im aktiven Dienst 1976 hat eine ständige Expansion der Bedürfnisse und der Gesamtaufgabe stattgefunden. ${ }^{43}$

Konzeptionell basierte das wachsende schweizerische Gesamtverteidigungssystem auf einem möglichst gleichberechtigten Zusammenspiel seiner militärischen und zivilen Teile. Nominell ging dieser Anspruch nach Gleichberechtigung mit einer Aufwertung des Zivilen und einem Bedeutungsverlust des Militärischen einher. Der zivile Alarmausschuss bzw. dessen

$5^{2}$ Vgl. Archiv BAG, 18.10.57, Alarmorganisation für den Fall erhöhter Radioaktivität, Note concernant l'entretien relatif à l'organisation d'alarme en cas d'augmentation de la radioactivité, 5.1.1971.

53 CH-BAR\#E439oC\#1997/14\#223*, Bedürfnisnachweis des Alarmausschusses der KUeR, 8.6.1979. 
Alarmorganisation besaßen jedoch nicht genügend Personal und Mittel, um Strahlenschutzmaßnahmen selbst durchzuführen, und auch der Zivilschutz war gerade im AC-Bereich stets schlechter ausgerüstet und ausgebildet als die Armee. Das Militär wiederum erklärte sich nur widerwillig bereit, dem Alarmausschuss seine Ressourcen zur Verfügung zu stellen. Faktisch wurde der Gleichberechtigungsanspruch auf dem Gebiet des Atomalarms und des Strahlenschutzes also nicht eingelöst. Dennoch erschwerte er es lange Zeit, dass ein Akteur die Verantwortung für den Gesamtkomplex der nuklearen Bedrohung übernehmen konnte.

Gleichzeitig führte das System der Gesamtverteidigung zu einem Koordinationsimperativ, wobei sich diejenigen Stellen, die eine Koordinationsleistung hätten übernehmen sollen, als zu wenig durchsetzungsfähig erwiesen. Die beteiligten Akteure blieben zudem in ihren zivilen oder militärischen Institutionen und Denkstilen verhaftet. So erwies sich die ,koordinierte Sicherheit' im Bereich des Atomalarms und des Strahlenschutzes immer als prekär. Es zeigt sich hier ein strukturelles Problem des expandierenden schweizerischen Gesamtverteidigungssystems, das einerseits eine möglichst weitgehende Zusammenarbeit seiner verschiedenen Teile postulierte, dadurch andererseits aber einen systemimmanenten Koordinationsbedarf aufwies, der nach einer klareren Führungsstruktur und einer stärkeren Hierarchisierung verlangt hätte. Koordination und Kooperation erwiesen sich indessen - wie das nächste Teilkapitel zeigt - auch bei der Informationsübermittlung innerhalb der Alarmorganisation als äußerst anspruchsvolle Daueraufgaben.

\section{2 Übermittlungsprobleme und Expansionsdynamiken. Praktischer Aufbau der Alarmorganisation, 1964-1984}

Ein rechtzeitiger und funktionierender Strahlenalarm setzte ein komplexes Alarmierungsdispositiv voraus. Um bei einem atomaren Notfall Strahlenschutzvorkehrungen in Gang setzen zu können, musste die Erhöhung der Radioaktivität zunächst registriert und gemessen werden. Nach einer vorläufigen groben Einschätzung der Verstrahlungssituation galt es daraufhin falls notwendig - unverzüglich erste Schutzmaßnahmen für die Bevölkerung anzuordnen. Gleichzeitig mussten die verfügbaren Strahlenschutzexperten und -gremien mobilisiert werden. Diese Spezialisten und Fachorgane sollten die Verstrahlungslage fortlaufend weiter analysieren und auswerten. Basierend auf dieser Beurteilung würden anschließend umfassende Schutzanweisungen beschlossen und die Behörden und die Bevölkerung entsprechend informiert. 
Damit die preparedness der Alarmorganisation sichergestellt war und das Alarmierungsdispositiv reibungslos funktionierte, bedurfte es eines möglichst koordinierten und störungsfreien Zusammenspiels zahlreicher Akteure, Instrumente und Systeme. Wie bereits dargestellt, bildete dies auf institutioneller Ebene ein permanentes Problem. In diesem Teilkapitel werde ich nun die praktische Funktionsweise der Alarmorganisation analysieren. Im Kern ging es bei der zu schaffenden Alarmorganisation darum, Radioaktivitätsmesswerte in Handlungsanweisungen zu übersetzen. Dabei kam der korrekten und raschen Übermittlung von Information eine bedeutende Rolle zu. Mit Bruno Latour lässt sich der Weg von den zu gewinnenden Messresultaten zu den anzuordnenden Strahlenschutzmaßnahmen als eine Kette von Übersetzungsprozessen verstehen, während derer die weiterzugebenden Informationen einer ständigen Transformation unterworfen waren. ${ }^{54}$ Die Strahleninformationen wurden innerhalb der Alarmorganisation somit fortlaufend umgeformt, reduziert und erweitert. Der Übersetzungsvorgang einer Meldung erhöhter Radioaktivität bis hin zum Ertönen einer Alarmsirene basierte damit auf vielfältigen Transformations- und Kommunikationsprozessen, die sich als anforderungsreich und störanfällig erwiesen. Dies umso mehr, da bei jedem Schritt auf mehreren Ebenen zahlreiche Akteure involviert waren, deren effiziente und koordinierte Zusammenarbeit eine enorme Herausforderung darstellte.

\section{Kontext(un)abhängige Transformationen und Übersetzungen}

Die vom Alarmausschuss geplante Alarmorganisation nahm Ende der 196oer, Anfang der 197oer Jahre konkrete Formen an. Für die Bewältigung eines angenommenen nuklearen Ereignisses definierte der Alarmausschuss drei zentrale Phasen, die idealtypisch chronologisch aufeinander folgen, sich in der Realität indessen zeitlich überschneiden würden. Ich werde das Alarmierungsdispositiv nun entlang dieser drei Phasen beschreiben und dabei auf zwei Anfang der 1970er Jahre erstellte Organisationsschemen Bezug nehmen. ${ }^{55}$ Dabei

54 Vgl. Latour 2002 [1999].

55 Die Ausführungen der folgenden vier Absätze basieren auf: CH-BAR\#E20o1E\#1980/ $83^{\#} 512 *$, Überblick über die vorauszusehenden und durchzuführenden Massnahmen im Falle einer Atombomben-Katastrophe in Friedenszeiten, 10.4.1968; Archiv BAG, 18.10.57a, Alarmzentrale, Überblick über die vorauszusehenden und durchzuführenden Massnahmen gegen die radioaktive Gefährdung im Falle einer AtombombenKatastrophe in Friedenszeiten, 6.4.1971; CH-BAR\#E3300C\#1993/155\#594*, Überblick über die vorauszusehenden und durchzuführenden Massnahmen gegen die radioaktive Gefährdung im Falle einer Atombombenkatastrophe in Friedenszeiten (Entwurf), 
wird sich zeigen, dass der Einsatz der mobilisierten Personen und Institutionen, Messinstrumente und Labororganisationen zwar von festgelegten Normen und Abläufen ausging, die tatsächliche preparedness der Alarmorganisation aber entscheidend von flexiblen Transformationen und Übersetzungsprozessen abhing, die dem Alarmausschuss einen möglichst großen Spielraum für Interventionen zur Steuerung der atomaren Katastrophe eröffnen sollten.

In der ersten Phase (Abb. 22) stand die Alarmierung von Behörden und der Bevölkerung im Zentrum. Die Überwachungszentrale der Alarmorganisation, die sich zunächst bei der Aerologischen Anstalt in Payerne und ab 1975 bei der Schweizerischen Meteorologischen Zentralanstalt in Zürich befand, musste jederzeit in der Lage sein, Meldungen aus dem schweizerischen und dem europäischen Überwachungsnetz entgegenzunehmen, um sich möglichst ohne Zeitverlust über ein allfälliges Nuklearereignis zu informieren. Als Informationsquellen aus dem Inland standen der Überwachungszentrale die fünf Frühwarnposten der Eidgenössischen Kommission zur Überwachung der Radioaktivität (KUeR) zur Verfügung, die in Grenznähe aufgestellt waren und bereits ein geringes Ansteigen der Radioaktivität in der Luft registrieren konnten. ${ }^{56}$ Daneben erhielt die Überwachungszentrale Informationen von den Atomwarnposten des Alarmausschusses. Hierbei handelte es sich um hauptsächlich von der Polizei bediente, über die Schweiz verteilte Stationen, bei denen Atomwarngeräte installiert waren, die beim Überschreiten einer bestimmten Dosisleistung Alarm auslösten. Bei den Atomwarnposten befanden sich zusätzlich tragbare Messgeräte, mit denen die Radioaktivität in der Umgebung gemessen werden konnte. Falls - etwa in einem Mobilmachungsfall bereits Angehörige des AC-Dienstes von Armee und Zivilschutz im Einsatz waren, konnten auch diese Stellen Beobachtungen und Messwerte an die Überwachungszentrale übermitteln. Aus dem Ausland erhielt die Überwachungszentrale zum einen Informationen über das Fluginformationsbüro im Flughafen Kloten, auch Notam-Büro genannt, in dem Meldungen über die Flugsicherheit zusammenflossen. Sollten Flugzeugbesatzungen Atomexplosionen feststellen, würde das Notam-Büro diese Information an die Überwachungszentrale weiterleiten. Zum anderen bestand seitens der Überwachungszentrale

4.11.1971; CH-BAR\#E439oC\#1977/164\#352*, Massnahmen gegen radioaktive Gefährdung. Schutzmassnahmen gegen die Gefährdung bei einer Atombombenkatastrophe in Friedenszeiten, Vorauflage des BZS, 4. Seminar für Regierungsräte betreffend Krisenmanagement, 4.-6.10.1972; Archiv BAG, 18.6.3, Alarmausschuss II. Teil, Radioaktive Gefährdung und mögliche Schutzmassnahmen bei einer Atombombenkatastrophe im Frieden, April 1973; CH-BAR\#E439oC\#1981/147\#238*, Radioaktive Gefährdung und mögliche Schutzmassnahmen bei einer Atombombenkatastrophe im Frieden, Oktober 1973. 


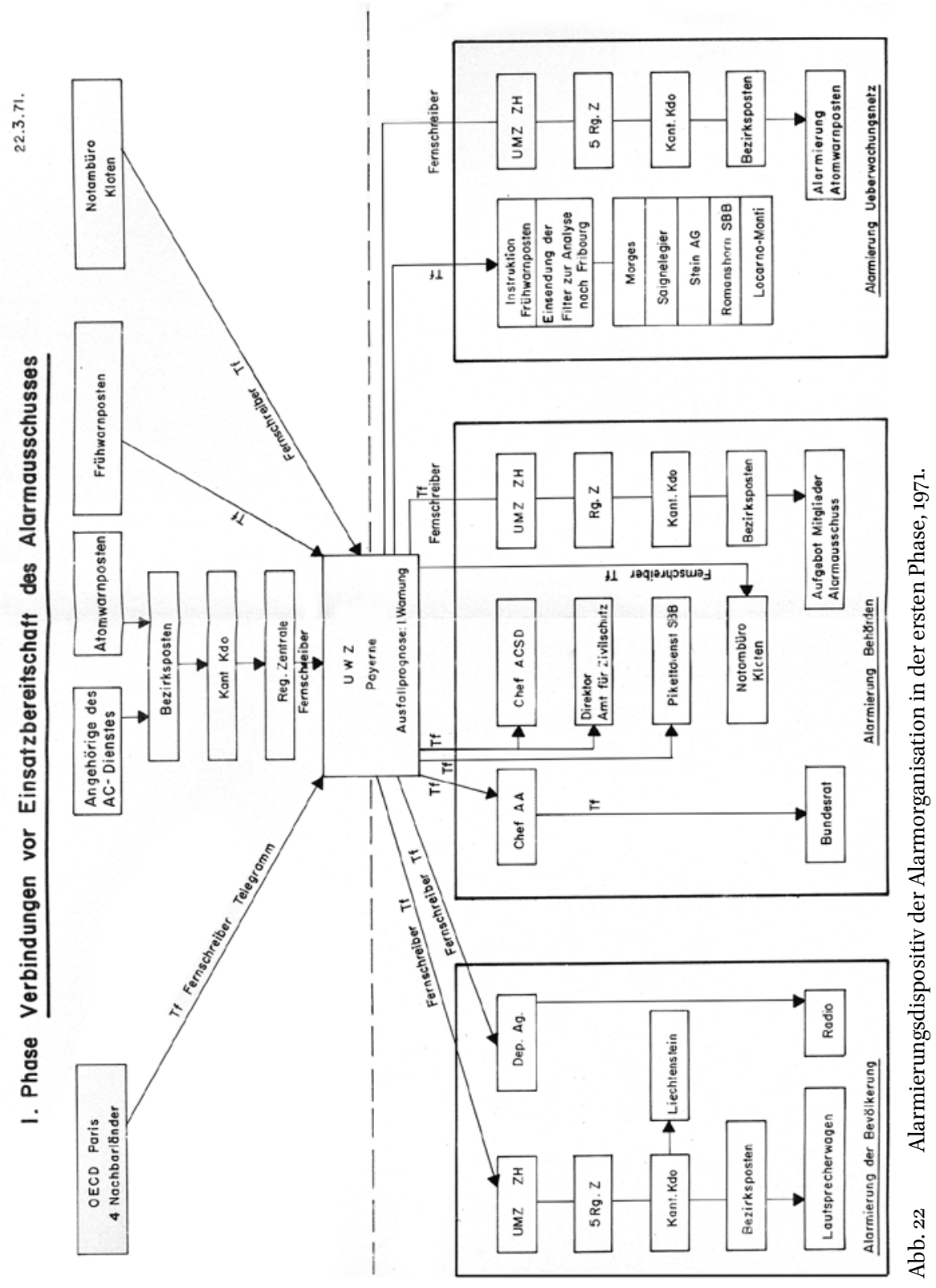


eine ständige Verbindung zur Alarmorganisation der OECD, an die auch alle Nachbarländer der Schweiz angeschlossen waren. ${ }^{57}$ Basierend auf allen verfügbaren Informationen über das Nuklearereignis und unter Berücksichtigung der meteorologischen Verhältnisse erstellte die Überwachungszentrale eine Prognose des radioaktiven Ausfalles und schätzte die daraus resultierenden Strahlungsdosen im Freien ab. Aufgrund dieser ersten Abschätzung der zu erwartenden Verstrahlungssituation erfolgte die Alarmierung. Bei einem nuklearen Notfall musste die Überwachungszentrale die in den Strahlenschutz involvierten Behörden, darunter die Chefs des Alarmausschusses und der Unterabteilung AC-Schutzdienst sowie den Direktor des Bundesamtes für Zivilschutz, mobilisieren. Trafen bei der Überwachungszentrale Meldungen und Warnungen über atomare Ereignisse aus dem Ausland ein, bevor der radioaktive Ausfall die Schweiz erreicht hatte, so musste die Überwachungszentrale auch das Überwachungsnetz der Alarmorganisation aktivieren. Die Frühwarnposten erhielten Instruktionen darüber, wann sie ihre Filter zur Analyse ins Labor der KUeR nach Fribourg zu senden hatten. Die Atomwarnposten wiederum befanden sich nicht ständig in Betrieb und mussten gegebenenfalls zuerst eingeschaltet werden. Die Hauptziele der ersten Phase bestanden aber selbstredend in der unverzüglichen Alarmierung der Bevölkerung und der Anordnung von ersten Schutzmaßnahmen. Dazu gehörten - abhängig von der Einschätzung der Gefährdungssituation - Anweisungen wie „im Haus bleiben“, „Fenster schliessen“, „Reinigung von radioaktivem Staub beim Eintritt aus dem Freien“ oder "Einweisung der Bevölkerung in Schutzräume“. Diese Verhaltensanweisungen wurden über das Radio oder über Lautsprecherwagen kommuniziert.

Die zweite Phase (Abb. 23) fokussierte darauf, Schutzmaßnahmen in genauer Kenntnis der Verstrahlungslage durchzuführen, was eine möglichst exakte Messung der Radioaktivität voraussetzte. Die Haupttätigkeit der Alarmorganisation verlagerte sich in dieser Phase von der Überwachungszentrale auf die Alarmzentrale in Bern. Letztere bildete fortan den Kern der Alarmorganisation, wo alle Informationen ein- und von wo sämtliche Weisungen ausgingen und wo sich nun auch der inzwischen einsatzbereite und für die Bewältigung des Nuklearereignisses hauptsächlich verantwortliche

57 Die OECD-Alarmorganisation bestand allerdings nur bis 1971 und wurde danach stillgelegt, wenn auch nicht aufgehoben. Vgl. Archiv BAG, 18.6.1, Eidg. Kommission zur Überwachung der Radioaktivität, der Luft und der Gewässer (KUeR), 1. Teil, Schreiben von W. Hunzinger an die KUeR, 17.1.1972. 


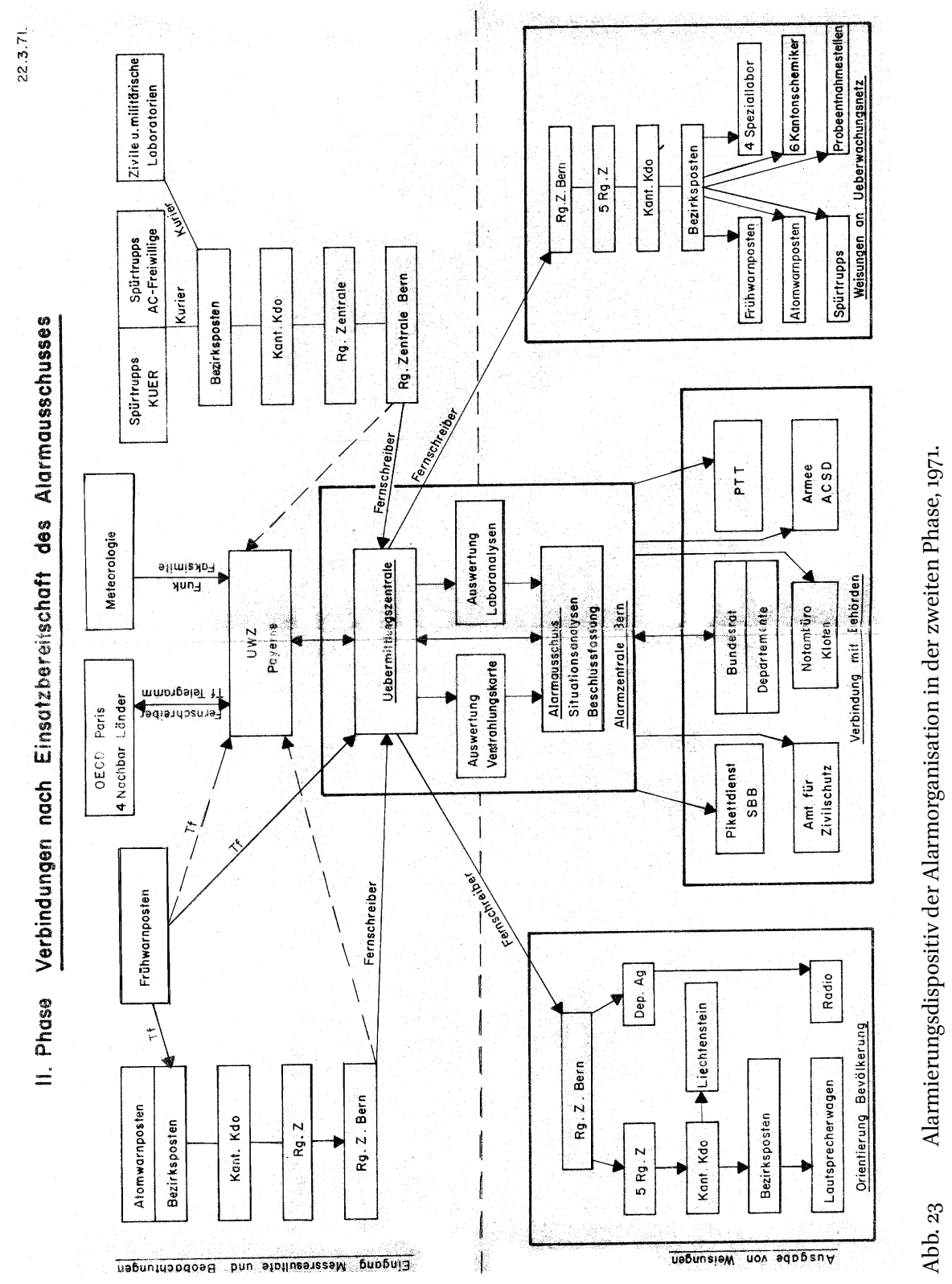


Alarmausschuss befand. ${ }^{58}$ Circa 20 Stunden nach dem Alarm waren nun verschiedene Spürtrupps, insbesondere die freiwillig tätigen AC-Spezialisten der Armee und die AC-Einheiten des Zivilschutzes, im Einsatz, um mit mobilen Spürgeräten die Dosisleistungen über dem Erdboden zu messen. ${ }^{59}$ Weitere Messungen nahmen die Pikettdienste [Bereitschaftsdienste] und Notfallequipen der Atomanlagen und die an verschiedenen Orten der Schweiz stationierten Messwagen der Strahlenschutzkontrolleure des Eidgenössischen Gesundheitsamtes vor. Ebenfalls im Einsatz war zu diesem Zeitpunkt die Labororganisation, welche damit begann, die Radioaktivitätsdosen verstrahlter Lebensmittel abzuschätzen. Diese bestand aus Laboratorien von Armee und Zivilschutz, den Laboratorien der Arbeitsgemeinschaft zur Überwachung der Radioaktivität der Lebensmittel sowie den Laboratorien der Physikalischen Institute der Universitäten Fribourg und Basel, der Eidgenössischen Anstalt für Wasserversorgung, Abwasserreinigung und Gewässerschutz und des Gesundheitsamtes. Hinzu kamen die über das Land verteilten Probenahmestellen für Zisternenwasser, Regenwasser, Milch, Gras und Lebensmittel, deren Verantwortliche dafür sorgen mussten, dass die entnommenen Proben zur Analyse an ein bestimmtes Laboratorium gelangten. ${ }^{60}$

In der Alarmzentrale wurden die fortlaufend eintreffenden Messresultate und Beobachtungen gesammelt und ausgewertet, Verstrahlungskarten und Laboranalysen erstellt, Situationsanalysen erarbeitet und Beschlüsse gefasst. Der Alarmausschuss sollte in dieser Phase imstande sein, sich ein immer genaueres Bild über die effektive Verstrahlungslage zu machen, um bei dem Bundesrat bzw. den zuständigen Departementen, der Armee, dem Zivilschutz und weiteren Behörden sowie den verschiedenen Stellen des Überwachungsnetzes die Durchführung umfassender Schutzmaßnahmen zu beantragen. ${ }^{61}$ Diese betrafen zum einen die Festlegung der notwendigen Aufenthaltsdauer im Schutzraum bzw. der erlaubten Aufenthaltsdauer im Haus oder im Freien, die Anordnung von ersten Dekontaminationsarbeiten sowie die Bestimmung des Zeitpunktes allfälliger Evakuierungen aus extrem stark kontaminierten

58 Bei Reaktorunfällen würde der Alarmausschuss mit der KSA zusammenarbeiten.

59 Fand die Atomkatastrophe nicht in Friedens-, sondern zu Zeiten aktiven Dienstes statt, waren diese Truppen bereits seit längerem aufgeboten.

6o Zum Messnetz dieser Probenahmestellen vgl. Kapitel 3.2.

61 Der Alarmausschuss war lediglich für die Beantragung von Schutzmaßnahmen, nicht aber für deren praktische Durchführung zuständig. Letzteres war Sache der Bundes-, Kantons- und Gemeindebehörden. Die Bezeichnung des Alarmausschusses als Ausführungsorgan bezog sich nur auf die Tätigkeiten des Messens, des Beurteilens, des Entscheidens und der Antragstellung bzw. der Orientierung. 
Gebieten. Zum anderen ging es um Maßnahmen der Lebensmittelversorgung, so etwa um die Versorgung der Bevölkerung aus eigenen Notvorräten, um die Sperrung von Frischlebensmitteln wie Milch, Fleisch, Gemüse und Obst oder um die Vorbereitung der Notversorgung in bestimmten Gebieten. ${ }^{62}$

In der dritten Phase wurden die begonnenen Arbeiten mit dem Ziel fortgeführt, die Lebensbedingungen wieder zu normalisieren. Die Leitung oblag immer noch dem Alarmausschuss, welcher sich nach wie vor in der Alarmzentrale befand. Die Labororganisation maß weiterhin die Verstrahlung von Lebens- und Futtermitteln, Trink- und Tränkewasser und führte spezifische Analysen besonders gefährlicher radioaktiver Spaltprodukte durch, um die effektiven Dosen der Radioaktivität in verstrahlten Lebensmitteln zu ermitteln. Der Alarmausschuss legte darauf aufbauend die Sperrdauer verstrahlter Lebensmittel fest, organisierte die Versorgung und ordnete spezifische Dekontaminationsarbeiten an. Mit der Zeit sollte es dem Alarmausschuss auch möglich sein, die angeordneten Schutzmaßnahmen nach und nach wieder zu lockern.

Überblickt man das vom Alarmausschuss entwickelte Alarmierungsdispositiv, so wird deutlich, dass die reziproke und reibungslose Weitergabe von Informationen zwischen sämtlichen involvierten Akteuren und Stellen für das Funktionieren der Alarmorganisation eine konstitutive Voraussetzung bildete. Allerdings waren diese Informationen innerhalb des Alarmierungsdispositivs ständigen Transformations- und Übersetzungsprozessen unterworfen. Dadurch veränderte sich der Inhalt der Informationen permanent und dies in mindestens dreierlei Hinsicht: Erstens veränderte sich der Inhalt der Informationen aus dem einfachen Grund, weil sich die Modalität der Sprechakte wandelte. Daten wurden zunächst in propositionale Aussagen und danach in Handlungsanweisungen übersetzt. Zweitens veränderte sich der Inhalt der Informationen, weil die Trägermedien der Informationen variierten. So galt es, die Aktivität von Radioisotopen zunächst in Zahlenwerte, danach in kartographische Repräsentationen - sogenannte Verstrahlungskarten - und anschließend in Texte - Situationsanalysen genannt - zu übersetzen. Schließlich waren diese Situationsanalysen, welche die Gefahrensituation deuteten, in Schutzanweisungen zu transformieren, die sich über Radio- oder Lautsprecherdurchsagen verbreiten ließen. Bei jedem dieser medialen Übersetzungsprozesse wurden gewisse Informationselemente konserviert und kondensiert, gleichzeitig fielen bestimmte Elemente weg und es kamen

62 Zu den Notvorräten im Kalten Krieg in der Schweiz: Marti 2014a. 
neue Elemente hinzu. ${ }^{63}$ Dies lässt sich an einem einfachen Beispiel verdeutlichen: Die Übersetzung von Radioaktivitätsmesswerten in Verstrahlungskarten brachte zwar neue Informationsinhalte über die räumliche Verteilung der Strahlung hervor. In den kartographischen Repräsentationen über die Topographie der Verstrahlung waren die exakten Zahlenwerte der einzelnen Messstationen aber nicht mehr ersichtlich. Drittens - und hier wesentlich veränderte sich der Inhalt der Informationen, weil die Übersetzungsprozesse nicht automatisiert, sondern situativ und kontextabhängig erfolgten. Anders als vermutet werden könnte, übersetzte der Alarmausschuss die eingehenden Informationen in der Alarmzentrale nicht nach einem standardisierten Verfahren in bestimmte Weisungen. Vielmehr konnten aus vergleichbaren Radioaktivitätsmesswerten - je nach Einschätzung und Deutung der Situation - unterschiedliche Schutzmaßnahmen resultieren. Insbesondere bei der Auswertung von Messresultaten und der Beurteilung von Situationsanalysen sowie bei der Formulierung von Handlungsanweisungen produzierte der Alarmausschuss in der Alarmzentrale selbst neues Wissen. Der Inhalt der Informationen veränderte sich innerhalb des Alarmierungsdispositivs also insbesondere auch deshalb, weil permanent Urteile und Deutungen von Akteuren involviert waren.

Ich möchte diesen letzten Punkt im Folgenden anhand des Beispiels der Anwendung und Interpretation von Toleranzdosen näher ausführen. Selbstredend war eine Atomexplosion oder ein Reaktorunfall im weit entfernten Ausland nicht mit dem gleichen Gefährdungspotenzial verbunden wie eine Atomkatastrophe im grenznahen Ausland oder im Inland. Das Alarmierungsdispositiv der Alarmorganisation differierte deshalb zwischen unterschiedlichen Bedrohungs- bzw. Alarmstufen, die jeweils andere Schutzmaßnahmen nach sich ziehen würden. Als Grundlage fungierten hier die von der Internationalen Strahlenschutzkommission ausgearbeiteten Jahrestoleranzdosen. ${ }^{64}$ Ein skandinavischer Bericht über Alarmstufen diente ebenfalls als Orientierungshilfe, und es wurde auch auf die Vorgaben der OECD-Alarmorganisation geachtet. ${ }^{65}$ Der Aufbau der Alarmorganisation orientierte sich also an deren Kompatibilität mit internationalen Normen und Alarmsystemen, wobei sich die Einteilung der Nuklearereignisse in die verschiedenen Stufen nach der Höhe der erwarteten Strahlendosen richtete.

63 Im Sinne Bruno Latours lassen sich solche Übersetzungsprozesse deshalb als Transformationsketten verstehen, die Referenz herstellen. Vgl. Latour 2002 [1999].

64 Vgl. CH-BAR\#E819oB-ol\#1986/181\#130*, Protokoll der 16. Sitzung der KUeR, 3.12.1959.

65 Vgl. ebd., Protokoll der 2o. Sitzung der KUeR, 5.11.196o. 
In Bezug auf die Bedrohungs- bzw. Alarmstufen war es dabei unerheblich, ob das zu bewältigende Nuklearereignis ziviler oder militärischer Art war. So ging der Alarmausschuss davon aus, dass sich - wie wiederholt betont wurde - im Fall eines Atomkrieges „grundsätzlich für die Schutz- und Abwehrmassnahmen die gleichen technischen Probleme wie bei einer Atombombenkatastrophe im Frieden [stellen]“. ${ }^{66}$ Diese - fragwürdige - Ähnlichkeitsbehauptung zwischen einem Atomkrieg und zivilen Nuklearkatastrophen stellte kein rein schweizerisches Phänomen dar. Vielmehr versuchte die zeitgenössische Katastrophenforschung, so etwa in den USA, gezielt, Erkenntnisse aus Naturkatastrophen und Industrieunfällen in die Vorbereitung auf einen künftigen Atomkrieg zu übertragen. Die Wissenschaftshistorikerin Sharon Ghamari-Tabrizi hat diesen Gleichsetzungsversuch als "grand analogy“ bezeichnet. ${ }^{67}$ Die im schweizerischen Kalten Krieg ausgeprägte Vermischung von zivilen und militärischen Strukturen und Ressourcen verstärkte die Plausibilität dieser Analogie.

Das Alarmierungsdispositiv differenzierte also nicht grundlegend, ob sich die Schweiz bei der Bewältigung einer Nuklearkatastrophe im Friedens- oder Kriegsfall befinden würde. Dies bedeutete jedoch nicht, dass der Kontext und die spezifische Situation, in der eine Nuklearkatastrophe stattfinden würde, keine Berücksichtigung fand. Die im Alarmierungsdispositiv festgeschriebenen Toleranzwerte für Radioaktivität waren nämlich nicht allein ausschlaggebend für die Festlegung von Schutzmaßnahmen. Vielmehr plädierte der Alarmausschuss dafür, diese Grenzwerte situativ flexibel und kontextabhängig zu handhaben. So hielten interne Richtlinien fest:

Grundsätzlich sind kleinere Dosen [als die Toleranzdosen] anzustreben; es hat aber keinen Sinn, grössere Sicherheitsfaktoren einzukalkulieren, da solche den Aufenthalt im Schutzraum unnötig verlängern und die Aufnahme des möglichst bald anzustrebenden öffentlichen Lebens stark verzögern. Im Falle extrem starker Verseuchungen über grössere Gebiete wird man sogar die Toleranz heraufsetzen und die möglichen Schädigungen in Kauf nehmen müssen. ${ }^{68}$

66 CH-BAR\#E330oC\#1993/155\#594*, Überblick über die vorauszusehenden und durchzuführenden Massnahmen gegen die radioaktive Gefährdung im Falle einer Atombombenkatastrophe in Friedenszeiten (Entwurf), 4.11.1971; CH-BAR\#E2001E\#1980/83\#512*, Überblick über die vorauszusehenden und durchzuführenden Massnahmen im Falle einer Atombomben-Katastrophe in Friedenszeiten, 10.4.1968.

67 Vgl. Ghamari-Tabrizi 2013, bes. S. 342.

68 CH-BAR\#E2001E\#1978/84\#1013*, Richtlinien für die Ausgabe der Orientierung und Weisungen an die Bevölkerung, 31.12.1966. 
Gleiches galt für die Festlegung der Aufenthaltsdauer in den Schutzräumen. Hier war deren Berechnung im Prinzip ebenfalls vorgegeben, doch auch hierzu hieß es: „In extremen Fällen, d.h. bei starken Ausfällen wird man allerdings eine höhere ,Toleranz-Dosis‘ in Kauf nehmen müssen.69 Dasselbe betraf die Festsetzung der Toleranzdosen für Spür- und Rettungstruppen, Polizei- und Notfalldienste, die sich möglicherweise noch während des Ausgehverbots ins Freie begeben müssten. Für diese Personen waren an sich bereits höhere Grenzwerte - sogenannte annehmbare Ernstfalldosen - vorgesehen als für die Gesamtbevölkerung, doch hier galt ebenso: „Bei sehr starken Verseuchungen [...] wird man Toleranz-Dosen festlegen müssen, wie sie für den kriegsmässigen Einsatz in der Armee [...] Gültigkeit haben“, wodurch „allerdings Schädigungen unvermeidlich sein [werden] ${ }^{4} .70$ Situationsbedingt musste auch entschieden werden, unter welchen Umständen Evakuierungen sinnvoll und durchführbar wären: „Die Frage, bei welchen Dosen, bzw. in welchem Zeitpunkt Evakuationen notwendig werden, wird von Fall zu Fall entschieden werden müssen. ${ }^{411}$ Hier war es vor allem von den verfügbaren Schutzräumen abhängig, wie die Antwort auf diese Frage ausfiel, denn: „Der längere Aufenthalt [...] in schlecht eingerichteten, überfüllten Schutzräumen wird bald unhaltbar [...]."72

Die zitierten internen Richtlinien verdeutlichen, dass die Mitglieder des Alarmausschusses in der Alarmzentrale ständig Urteile zu fällen und Interpretationen vorzunehmen hatten. Dieses menschliche Handeln beeinflusste die Übersetzungsprozesse und bestimmte maßgeblich mit, welchen Transformationen die Informationen innerhalb des Alarmierungsdispositivs unterworfen waren. Konkret hieß dies, dass jemand abschätzen und entscheiden musste, ob eine bestimmte Situation die Heraufsetzung von Toleranzgrenzen rechtfertigte oder nicht. Die aufgestellten Toleranzdosen dienten eigentlich dem Zweck, Entscheidungsverantwortung an festgelegte Regelwerke zu delegieren. Die Quellenzitate zeigen indessen, dass explizit kein solcher Automatismus angestrebt wurde. So gingen die Richtlinien davon aus, dass bei bestimmten nuklearen Katastrophen die Überschreitung von Grenzwerten und damit Gesundheitsschädigungen bei der Bevölkerung oder bei Schutz- und Rettungstruppen in Kauf genommen werden mussten. Entscheidend für das Funktionieren des Alarmierungsdispositivs waren folglich nicht nur wissenschaftlich-medizinische Kriterien und internationale

\footnotetext{
$69 \quad$ Ebd.

70 Ebd.

71 Ebd., Die Dosen in Schutzräumen bei starken radioaktiven Verseuchungen, 25.8.1967.

72 Ebd., Richtlinien für die Ausgabe der Orientierung und Weisungen an die Bevölkerung, 31.12.1966.
} 
Strahlenschutznormen, sondern vielmehr auch politische, militärische und soziale Einschätzungen der verantwortlichen Entscheidungsträger aus Politik und Gesamtverteidigung. Aus gouvernementaler Sicht sollte das Alarmierungsdispositiv eine möglichst große Flexibilität und damit einen möglichst breiten Handlungsspielraum für steuernde Interventionen bieten. Für das Regieren von Strahlen bei einem atomaren Notfall kam den Deutungen und Beschlüssen der in die Alarmorganisation involvierten Akteure folglich eine zentrale Rolle zu. Dieser menschliche Faktor stellte potenziell eine Fehlerquelle dar. Das Alarmierungsdispositiv war aber auch aus anderen Gründen störanfällig.

\section{Übermittlungs(um)wege und (Des-)Orientierungen}

Das Alarmierungsdispositiv der Alarmorganisation bildete auch in kommunikativer Hinsicht ein enorm voraussetzungsreiches System. Vergegenwärtigt man sich nochmals die beiden Organisationsschemen der Alarmorganisation von Anfang der 1970er Jahre (Abb. 22 und 23), so wird deutlich, dass das Alarmierungsdispositiv in erheblichem Maß auf ein funktionierendes Übermittlungsnetz angewiesen war. Dieses Übermittlungsnetz stützte sich auf verschiedene Verbindungskanäle, so hauptsächlich auf Telefon, Fernschreiber und Radio. Kommunikation war jedoch stets prekär. Verbindungskanäle konnten - gerade in Katastrophensituationen - aufgrund von Überlastung oder Zerstörung ausfallen. Die Sicherstellung der Verbindungen zwischen den verschiedenen Teilen und Komponenten der Alarmorganisation stellte somit eine Achillesferse des Alarmierungsdispositivs dar. Ein effizienter und effektiver Strahlenalarm bedingte nicht nur komplexe Übersetzungsprozesse, sondern auch störungsresistente Kommunikationsnetze.

Übermittlungsprobleme konnten bei sämtlichen Verbindungen des Alarmierungsdispositivs auftreten, angefangen bei den bei der Überwachungszentrale einlaufenden Meldungen und Warnungen. Insbesondere bei Atomkatastrophen im Ausland befürchtete der Alarmausschuss, dass die Angaben über das Nuklearereignis - beispielsweise Ort, Zeit, Kaliber und Explosionsart einer Atombombe - „in den meisten Fällen innert nützlicher Frist nicht zur Verfügung stehen, oder dass sie widersprüchlich, unüberprüfbar oder unglaubwürdig sind.“73 Die Überwachungszentrale musste die ersten Maßnahmen deshalb in Unkenntnis der effektiven Gefahrensituation anordnen. Dies beweist wiederum die bereits erläuterte maßgebliche Bedeutung, welche den Urteilen und Deutungen der verantwortlichen Akteure

73 CH-BAR\#E330oC\#1993/155\#594*, Überblick über die vorauszusehenden und durchzuführenden Massnahmen gegen die radioaktive Gefährdung im Falle einer Atombombenkatastrophe in Friedenszeiten (Entwurf), 4.11.1971. 
zukam. Auch nachdem die Überwachungszentrale über ein mögliches Atomereignis informiert war, stellten sich grundlegende Übermittlungsprobleme. Zivile Verbindungsnetze galten als besonders störanfällig. Der Alarmausschuss betrachtete insbesondere "die bei einer Katastrophe zu erwartende Ueberlastung des Telephonnetzes" als Problem und sah deshalb vor, die Bevölkerung dazu anzuhalten, "die Telephonverbindungen zugunsten der Organe der Katastrophenhilfe freizuhalten“. ${ }^{74}$ Im ungünstigsten Fall einer Atomexplosion im eigenen Land ging der Alarmausschuss davon aus, dass „in grossen Gebieten die Verbindungen ganz ausfallen [werden]. [...] Meldungen können dann nur noch über die Radiosender, ev. Notsender durchgegeben werden.“75 Gleichwohl sollten die schweizerischen Post-, Telefon- und Telegrafenbetriebe aufgefordert werden, unterbrochene Fernmeldeverbindungen „im Rahmen des Möglichen“ wiederherzustellen. ${ }^{76}$ Auch das Radio bildete indessen keine sichere Übermittlungsquelle, könnte doch auch der Fall einer „Nicht-Betriebsbereitschaft der Radiosender" eintreten. ${ }^{77}$ Neben Telefon, Fernschreiber und Radio konnte die Alarmorganisation für die Übermittlung von Nachrichten einzig auf das Verbindungsnetz der Polizei zurückgreifen. „Dank dem Verständnis der kantonalen Polizeidirektoren und der Polizeikommandanten" - so der Alarmausschuss - könne sich die Alarmorganisation „dieser Verbindungsmöglichkeit bedienen“. ${ }^{78}$ Zwar besaß auch das Militär ein von zivilen Verbindungen unabhängiges Nachrichtennetz. Die militärischen Verbindungsmittel waren jedoch nur im Fall einer Mobilmachung der Armee verfügbar, nicht aber bei einer Atomkatastrophe in Friedenszeiten, und blieben für die Alarmorganisation auch in Kriegszeiten nur eingeschränkt nutzbar. ${ }^{79}$ Hier zeigt sich einmal mehr das Grundproblem der schweizerischen Gesamtverteidigung: Das Militär wäre zwar im Besitz bestimmter Ressourcen und

74 Ebd.

75 Archiv BAG, 18.10.57a, Alarmzentrale, Überblick über die vorauszusehenden und durchzuführenden Massnahmen gegen die radioaktive Gefährdung im Falle einer AtombombenKatastrophe in Friedenszeiten, 6.4.1971.

76 CH-BAR\#E439oC\#1981/147\#238*, Radioaktive Gefährdung und mögliche Schutzmassnahmen bei einer Atombombenkatastrophe im Frieden, Oktober 1973.

77 CH-BAR\#E2001E\#1980/83\#512*, Ueberblick über die vorauszusehenden und durchzuführenden Massnahmen im Falle einer Atombomben-Katastrophe in Friedenszeiten, 10.4.1968.

78 Archiv BAG, 18.10.57a, Alarmzentrale, Überblick über die vorauszusehenden und durchzuführenden Massnahmen gegen die radioaktive Gefährdung im Falle einer AtombombenKatastrophe in Friedenszeiten, 6.4.1971.

79 Vgl. CH-BAR\#E2001E\#1980/83\#512*, Ueberblick über die vorauszusehenden und durchzuführenden Massnahmen im Falle einer Atombomben-Katastrophe in Friedenszeiten, 10.4.1968. 
Mittel - etwa eines unabhängigen Verbindungs- bzw. Nachrichtennetzes -, diese stehen im Frieden aber prinzipiell nicht zur Verfügung und werden im Aktivdienstfall in erster Linie von der Armee selbst beansprucht.

Doch nicht nur bei direkten Kommunikationskanälen, sondern auch bei Verkehrsverbindungen bestand die Gefahr, dass diese bei Atomkatastrophen ausfielen. „Auf gewissen Strecken“ hielt der Alarmausschuss die Einstellung des Verkehrs für wahrscheinlich. ${ }^{80}$ Ebenso ging er davon aus, dass bei einer schweren Verstrahlungssituation „Boten mit Fahrzeugen nur in wenigen Fällen" einsetzbar wären. ${ }^{81}$ Verkehrsbehinderungen würden nicht nur die Tätigkeit von Schutz-, Rettungs- und Ordnungsdiensten, sondern auch die Arbeit von Kurieren beeinträchtigen. So könnten etwa Proben verseuchter Lebensmittel nicht oder nur unter erschwerten Bedingungen in die vorbestimmten Laboratorien transportiert werden. „Beim Zusammenbruch der Nachrichten- und Transportverbindungen" würden - so vermutete der Alarmausschuss - auch bei der Labororganisation „besondere Organisationsprobleme auftreten". ${ }^{82}$ Die essenzielle Anforderung, die Informationsübermittlung der Alarmorganisation jederzeit sicherzustellen, bildete folglich eine enorme Herausforderung. Deshalb wurden die Kommunikationsverbindungen in Alarmübungen auch regelmäßig trainiert. ${ }^{83}$

So fand beispielsweise im März 1976 eine Übung des Alarmausschusses unter dem originellen Namen „Knallfrosch“ statt. Ziel der Übung war es, die Alarmierung der Mitglieder des Alarmausschusses, die Aktivierung der Atomwarnposten und die Einrichtung der Alarmzentrale zu testen. ${ }^{84}$ Nach der Übung erreichte den Alarmausschuss ein Schreiben des Polizeikommandanten des Kantons Aargau, in welchem sich dieser für eine entstandene „Fehlleistung" entschuldigte: Das aargauische Polizeikommando hatte es nämlich zunächst versäumt, den über Fernschreiber eingegangenen Alarmbefehl an die Atomwarnposten weiterzugeben. Diese verzögerte Weiteralarmierung - so der Aargauer Polizeikommandant - sei nicht nur darauf zurückzuführen, dass

8o CH-BAR\#E330oC\#1993/155\#594*, Überblick über die vorauszusehenden und durchzuführenden Massnahmen gegen die radioaktive Gefährdung im Falle einer Atombombenkatastrophe in Friedenszeiten (Entwurf), 4.11.1971.

81 Archiv BAG, 18.10.57a, Alarmzentrale, Überblick über die vorauszusehenden und durchzuführenden Massnahmen gegen die radioaktive Gefährdung im Falle einer AtombombenKatastrophe in Friedenszeiten, 6.4.1971.

82 Ebd.

83 Vgl. bspw. CH-BAR\#E3300C\#1996/290\#517*, Bericht der Übungsleitung über die Übung PROVA (Entwurf), 26.10.1979, und Uebung PROVA DUE: Stellungnahme der AGr. J zum Übungsablauf, 27.1.1981; CH-BAR\#E330oC\#1996/289\#583*, Uebung Prova Tre des AA, 10.9.1982.

84 Vgl. CH-BAR\#E330oC\#1993/154\#657*, Übung „Knallfrosch“, 9.2.1975. 
das Polizeikommando während der Nachtzeit „mangels personeller Mittel“ nicht besetzt sei. Vielmehr handle es sich um

eine eindeutige Fehlleistung. Die FS-Einträge [Fernschreiber-Einträge] werden gleichzeitig auch auf dem Bezirksposten Aarau weitergegeben. Am 12.3.1976 leistete dort ein junger Polizeibeamter Dienst, für den „KUER“, „Knallfrosch“ und "Gamma uno" nur böhmische Dörfer waren. Infolge einer „Fehlschaltung" unterliess er es, den Pikettdienst Leistenden zu unterrichten. ${ }^{85}$

Wie der Polizeikommandant des Kantons Aargau versicherte, habe er inzwischen dafür gesorgt, „dass künftig Derartiges vermieden wird [...]." ${ }^{\text {“86 }}$ Die „Knallfrosch“-Alarmübung zeigt, dass die Kommunikation im Alarmierungsdispositiv jederzeit abbrechen konnte, selbst wenn die Verbindungskanäle an sich einwandfrei funktionierten. Störpotenziale und Fehlerquellen beim Strahlenalarm konnten also sowohl durch technisches als auch durch menschliches Versagen begründet sein: Der für die preparedness des schweizerischen Kalten Krieges entscheidende Einbezug einer großen Anzahl von Personen und Institutionen machte die Alarmorganisation folglich fehleranfällig.

Dem Alarmausschuss war sehr wohl bewusst, dass das reibungslose Funktionieren der Alarmorganisation nicht unwesentlich von einer möglichst fehlerfreien Informationsübermittlung abhing. Deswegen befassten sich von Beginn an mehrere Arbeitsgruppen über Jahre hinweg mit den Problemen des Nachrichtenflusses. ${ }^{87}$ Wohlgemerkt, die Kommunikation blieb prekär. Dies verdeutlichten insbesondere die während des Kalten Krieges regelmäßig stattfindenden Landes- und Gesamtverteidigungsübungen, anlässlich welcher jeweils auch das Dispositiv für den Strahlenalarm geprobt wurde. Mal für Mal gelangten die Auswertungsberichte der nationalen Verteidigungsübungen zum Ergebnis, das Alarmierungsdispositiv gegen Strahlen weise noch beträchtliche Mängel auf. 88 Übermittlungs- und Orientierungsprobleme gingen immer mit Koordinationsproblemen einher und verstärkten sich wechselseitig. Dies zeigte sich indessen nicht nur bei Notfallübungen, sondern auch bei tatsächlichen Katastrophenereignissen. So kam es - wie das Eidgenössische Verkehrsund Energiewirtschaftsdepartement und das Eidgenössische Departement des Innern (EDI) im Rückblick einhellig festhielten - anlässlich des Kernkraftwerkunfalls im US-amerikanischen Harrisburg Ende März 1979 „zu einem

85 Ebd., Schreiben des Polizeikommandanten des Kantons Aargau an die KUeR, 25·3.1976.

86 Ebd.

87 Vgl. bspw. CH-BAR\#E439oC\#1997/14\#230*, Schema der Organisation des AA im Alarmfall, ohne Datum.

88 Vgl. dazu Kapitel 5. 
Informationschaos, weil die Informationen aus verschiedensten Quellen weiterverbreitet wurden. ${ }^{489}$ Eine eingespielte Koordination setzte also eine funktionierende Kommunikation voraus und umgekehrt.

Der Alarmausschuss selbst hatte bereits Ende 1975 darauf hingewiesen, „dass einerseits die Alarmierung der Bevölkerung bei einem Schadenereignis nicht sichergestellt ist und andererseits die Information nach einem Alarm geregelt werden muss. ${ }^{40}$ Diese negative Einschätzung des Alarmausschusses ist in erster Linie auf medientechnische Einschränkungen der Mitte der 197oer Jahre verfügbaren Kommunikationsmittel zurückzuführen. Das Alarmierungsdispositiv der Alarmorganisation sah die Orientierung der Bevölkerung primär über Radio, ferner über Telefonrundspruch oder Presse vor. Diese Warnmöglichkeiten standen indessen nicht rund um die Uhr zur Verfügung. Gleichwohl sollte die Überwachungszentrale der Alarmorganisation dazu in der Lage sein, die Bevölkerung bei einem nuklearen Notfall innerhalb weniger Minuten zum Aufsuchen der Schutzräume aufzufordern. Der Alarmausschuss, der selbst über kein eigenes Alarmierungsnetz verfügte, beabsichtigte deshalb, für den Strahlenalarm auf das aus Sirenen bestehende Alarmierungssystem des Zivilschutzes zurückzugreifen. ${ }^{91}$

Beim Bundesamt für Zivilschutz gab es jedoch zunächst Widerstände gegen dieses Vorhaben. Dafür waren ein bestimmtes Bedrohungsbild sowie beschränkte Ressourcen ausschlaggebend. So war die Konzeption des Zivilschutzes seit dem Beginn des Kalten Krieges maßgeblich auf das Szenario eines Atomkrieges ausgerichtet. ${ }^{92}$ Der Zivilschutz fokussierte sich deshalb auf die Vorbereitung von Schutzmaßnahmen für einen künftigen Atomkriegsfall. Aufgrund begrenzter finanzieller Mittel genoss dabei die Vorbereitung der Schutzräume und die Sicherstellung eines reibungslosen Schutzraumbezuges erste Priorität. Das Alarmierungsproblem galt demgegenüber als weniger dringlich, und eine Mithilfe beim Problem des Strahlenalarms in Friedenszeiten kam für das Zivilschutzamt erst in Betracht, wenn der Vorbereitungsstand für den Kriegsfall weiter fortgeschritten war. ${ }^{93}$ Daher opponierte das Bundesamt für Zivilschutz gegen eine von einer Arbeitsgruppe des Ausschusses

89 CH-BAR\#E439oC\#1997/14\#526*, Antrag des EVED und des EDI, 16.9.1982.

9o Ebd., Aktennotiz der Besprechung betreffend Alarmierung und Informierung der Bevölkerung bei radioaktiver Verstrahlung, 18.12.1975, Hervorh. i. Orig.

91 Vgl CH-BARE439oC\#1981/147\#238*, Schreiben von O. Huber an H. Mumenthaler, 23.5.1975.

92 Vgl. Deville/Guggenheim 2015, bes. S. 272-281.

93 Vgl. CH-BAR\#E439oC\#1981/147\#238*, Alarmierungsmöglichkeiten der Bevölkerung bei gefährlich erhöhter Radioaktivität, 19.6.1975, und Schreiben von H. Mumenthaler an O. Huber, 9.9.1975. 
AC-Schutz im Auftrag des Stabes für Gesamtverteidigung erstellte Studie, ${ }^{94}$ die zu dem Schluss kam, das Sirenensystem des Zivilschutzes müsse „in jedem Katastrophenfall zur Verfügung stehen, nicht nur im Neutralitätsschutz- oder im Verteidigungsfall. “95

In den 1970er Jahren weiteten sich die imaginierten atomaren Bedrohungsvorstellungen aus. Neben den Atomkrieg traten mögliche zivile Nuklearkatastrophen wie Unfälle in Kernkraftwerken oder bei Transporten von Nuklearwaffen, Sabotageakte in Atomanlagen sowie unbeabsichtigte Atombombenexplosionen und Kernwaffentests. ${ }^{96}$ Diese vielfältigen nuklearen Bedrohungen, die völlig unerwartet und sehr schnell eintreten konnten, verlangten nach einer raschen Alarmierung der Bevölkerung. Demgegenüber gingen Nuklearkriegsszenarien gemeinhin von einer Eskalationsphase vor dem Ausbrechen des kriegerischen Konfliktes aus, sodass jeweils genügend Zeit vorhanden wäre, um Schutzmaßnahmen, insbesondere den vorsorglichen Schutzraumbezug, anzuordnen. ${ }^{97}$ Das Konzept des vorsorglichen Schutzraumbezuges half bei plötzlich ausbrechenden Atomkatastrophen folglich nicht mehr weiter. Vielmehr avancierte nun „der Schnellbezug des Schutzraums" zum zentralen Problem. ${ }^{98}$ Dies erkannte man auch im Bundesamt für Zivilschutz. Wolle man - so hielt ein Mitarbeiter Mitte der 1970er Jahre fest - „die Schutzmassnahmen so gestalten, dass sie kriegsbildunabhängig sind, kann auf das akustische Alarmmittel nicht verzichtet werden."99 Für eine unverzügliche Warnung der Bevölkerung kamen also nur Sirenen infrage. Über ein Alarmierungssystem mit Sirenen verfügte in der Schweiz jedoch nur die Zivilschutzorganisation.

Nachdem die Gesamtverteidigungsübung des Jahres 1977 hinsichtlich der Alarmierung der Bevölkerung erneut größere Lücken aufgezeigt hatte, setzte der Stab für Gesamtverteidigung 1978 eine Studiengruppe Warnung und Alarmierung ein. ${ }^{100}$ Diese sollte das Problemfeld Warnung und Alarmierung

94 Vgl. CH-BAR\#E330oC\#1993/156\#56o*, Bildung einer Studiengruppe „Warnung und Alarmierung": Auftrag und Zusammensetzung, 13.4.1978.

95 CH-BAR\#E439oC\#1997/14\#229*, Alarmierung und Informierung der Bevölkerung bei radioaktiver Verstrahlung; Zuständigkeit im Frieden, Mai 1977.

96 Vgl. ebd. Transportunfälle mit Atomwaffen passierten 1964 im US-Bundesstaat Maryland und 1966 im spanischen Palomares.

97 Vgl. CH-BAR\#E439oC\#1997/14\#526*, Standortbestimmung und einige Gedanken über die Alarmsirenen des Zivilschutzes, 9.9.1975.

98 Brenner 1982, S. 23.

99 CH-BAR\#E439oC\#1997/14\#526*, Standortbestimmung und einige Gedanken über die Alarmsirenen des Zivilschutzes, 9.9.1975.

100 Vgl. CH-BAR\#E568oC\#1998/161\#122*, Beilage 1 des Berichts über den Stand Ende 1979 der Auswertung der Gesamtverteidigungsübung 1977, ohne Datum, und Beilage 2 des 
vor dem Hintergrund der aktuellen sowie der künftig zu erwartenden Bedrohungsszenarien gesamthaft studieren und für jeden Fall die erforderlichen Organe, Zuständigkeiten und Verfahren, die geeigneten Mittel und Medien sowie die anzuordnenden Verhaltensanweisungen bestimmen. Unter der Leitung der Zentralstelle für Gesamtverteidigung (ZGV) fungierten Vertreter des Alarmausschusses, der Meteorologischen Zentralanstalt, des Bundesamtes für Zivilschutz, der Abteilung AC-Schutzdienst, der Abteilung Territorialdienst sowie der Kantone als Mitglieder. ${ }^{101}$ Die Studiengruppe entwarf ein Merkblatt für die Alarmierung der Bevölkerung, das ab September 1980 jeweils auf der zweitletzten Seite der Telefonbücher publiziert wurde (Abb. 24). Dieses Merkblatt diente dazu - wie die ZGV in einem Pressecommuniqué erläuterte -, „die Bevölkerung mit den Sirenenzeichen bekannt zu machen, die sie bei bevorstehenden Gefahren kurzfristig zu einer bestimmten Reaktion veranlassen. ${ }^{102}$ $\mathrm{Zu}$ diesen „bevorstehenden Gefahren“ zählte selbstredend auch eine gefährliche Erhöhung der Radioaktivität, weshalb das Merkblatt auch über das richtige Verhalten bei Strahlenalarm informierte.

Die Dringlichkeit, welche dem Strahlenalarm nach der Gesamtverteidigungsübung 1977 zugeschrieben wurde und die in der Einsetzung der Studiengruppe Warnung und Alarmierung des Stabes für Gesamtverteidigung ihren Ausdruck fand, führte dazu, dass das Bundesamt für Zivilschutz seine Widerstände aufgeben musste. Anfang der 1980er Jahre erließ es Weisungen zum Ausbau des Sirenen-Netzes auf Gemeindeebene, wobei der Bund die Revision und Ergänzung der Alarmsirenen subventionierte. ${ }^{103}$ Das schweizerische Alarmierungssystem umfasste schließlich sowohl stationäre als auch mobile Sirenen und sollte mit einer maximalen Alarmierungszeit von 30 Minuten sämtliche Einwohnerinnen und Einwohner erreichen. ${ }^{104}$ War ein unterbrochener an- und abschwellender Heulton von zwei Minuten zu hören, konnte man dies durch einen Blick auf das Merkblatt im Telefonbuch

Berichts über den Stand Ende 1979 der Auswertung der Gesamtverteidigungsübung 1977 (2. Teil), ohne Datum.

101 Vgl. CH-BAR\#E3300C\#1993/156\#560*, Bildung einer Studiengruppe „Warnung und Alarmierung": Auftrag und Zusammensetzung, 13.4.1978.

102 CH-BAR\#E439oC\#1997/14\#223*, Pressecommuniqué betreffend Merkblatt für die Alarmierung der Bevölkerung, 1.9.1980.

103 Vgl. CH-BAR\#E330oC\#1996/214\#694*, Weisungen des Bundesamtes für Zivilschutz über die Verdichtung der Zivilschutz-Alarmierungsnetze, 1.7.1981; CH-BAR\#E819oC\#1993/ 149\#49*, Protokoll der Informationstagung über die Alarmorganisation in der Umgebung der Kernkraftwerke, 4.1.1982. Viele der bereits vorhandenen Sirenen stammten noch aus der Zwischenkriegszeit.

104 Vgl. CH-BAR\#E819oC\#1993/149\#49*, Protokoll der Informationstagung über die Alarmorganisation in der Umgebung der Kernkraftwerke, 4.1.1982. 


\begin{tabular}{|c|c|}
\hline \multicolumn{2}{|c|}{$\begin{array}{l}\text { Alarmierung der Bevölkerung in Friedenszeiten } \\
\text { Alarme de la population en temps de paix } \\
\text { Allarme per la popolazione in tempo di pace }\end{array}$} \\
\hline $\begin{array}{l}\text { Sirenenzeichen und ihre Bedeutung } \\
\text { Signaux par sirènes et leur signification } \\
\text { Segnali d'allarme con sirene e loro significato }\end{array}$ & $\begin{array}{l}\text { Verhalten } \\
\text { Comportement } \\
\text { Comportamento }\end{array}$ \\
\hline $\begin{array}{l}\text { Allgemeiner Alarm } \\
\text { Alarme générale } \\
\text { Allarme generale }\end{array}$ & $\begin{array}{l}\text { Radio hören } \\
\text { Ecouter la radio } \\
\text { Ascoltare la radio }\end{array}$ \\
\hline $\begin{array}{l}\text { An- und abschwellender Heulton von } 1 \text { Minute } \\
\text { Ankündigung von Verhaltensanweisungen }\end{array}$ & $\begin{array}{l}\text { Anweisungen der Behörden befolgen, die über Radio, Telefon- } \\
\text { rundspruch oder durch weitere Informationsmittel verbreitet werden. } \\
\text { Nachbarn informieren. }\end{array}$ \\
\hline $\begin{array}{l}\text { Son oscillant continu durant } 1 \text { minute } \\
\text { Annonce la diffusion d'instructions sur le comportement }\end{array}$ & $\begin{array}{l}\text { Se conformer aux directives des autorités diffusées par radio, télé- } \\
\text { diftusion ou par d'autres moyens d'information. Informer les voisins. }\end{array}$ \\
\hline $\begin{array}{l}\text { Ululo modulato della durata di } 1 \text { minuto } \\
\text { Annuncio che saranno diffuse istruzioni di comporta- } \\
\text { mento }\end{array}$ & $\begin{array}{l}\text { Attenersi alle istruzioni delle autorità diffuse per radio, telediffusione } \\
\text { o con altri mezzi d'informazione. Informare i vicini. }\end{array}$ \\
\hline $\begin{array}{l}\text { Strahlenalarm } \\
\text { Alarme radioactivité } \\
\text { Allarme radioattività }\end{array}$ & $\begin{array}{l}\text { Schutz suchen } \\
\text { Se mettre à l'abri } \\
\text { Cercare riparo }\end{array}$ \\
\hline $\begin{array}{l}\text { Unterbrochener an- und abschwellender Heulton von } \\
2 \text { Minuten } \\
\text { Gefahrdung steht unmittelbar bevor }\end{array}$ & $\begin{array}{l}\text { Türen und Fenster schliessen. Sofort nächstgelegenen Schutzraum } \\
\text { oder Keller aufsuchen. Transistorradio mitnehmen und weitere An- } \\
\text { weisungen befolgen. }\end{array}$ \\
\hline $\begin{array}{l}\text { Séquences de sons oscillants durant } 2 \text { minutes } \\
\text { Danger imminent }\end{array}$ & $\begin{array}{l}\text { Fermer portes et fenêtres. Gagner immédiatement l'abri ou la cave } \\
\text { la plus proche. Emporter un transistor et suivre les instructions qui } \\
\text { y seront données. }\end{array}$ \\
\hline $\begin{array}{l}\text { Sequenze di ululi modulati della durata di } 2 \text { minuti } \\
\text { Pericolo imminente }\end{array}$ & $\begin{array}{l}\text { Chiudere porte e finestre. Raggiungere immediatamente il rifugio o } \\
\text { scantinato più vicino. Portare con sò la radio a transistori ed osser- } \\
\text { vare le istruzioni diffuse ulteriormente. }\end{array}$ \\
\hline $\begin{array}{l}\text { Wasseralarm } \\
\text { Alarme eau } \\
\text { Allarme acqua }\end{array}$ & $\begin{array}{l}\text { Gefährdetes Gebiet verlassen } \\
\text { Quitter la zone dangereuse } \\
\text { Abbandonare la zona pericolosa }\end{array}$ \\
\hline $\begin{array}{l}\text { Unterbrochener tiefer Ton von } 6 \text { Minuten } \\
\text { Oberflutungsgefahr in der Nahzone der Talsperren }\end{array}$ & $\begin{array}{l}\text { Oberflutungsgefăhrdetes Gebiet sofort verlassen; örtliche Merkblătter } \\
\text { oder Anweisungen beachten. }\end{array}$ \\
\hline $\begin{array}{l}\text { Séquences de sons graves durant } 6 \text { minutes } \\
\text { Danger d'inondation dans la zone rapprochée des bar- } \\
\text { rages }\end{array}$ & $\begin{array}{l}\text { Quitter immédiatement la zone menacée d'inondation; se conformer } \\
\text { aux instructions ou prescriptions locales. }\end{array}$ \\
\hline $\begin{array}{l}\text { Sequenze di suoni gravi della durata di } 6 \text { minuti } \\
\text { Pericolo d'inondazione nella zona vicina agli sbarramenti }\end{array}$ & $\begin{array}{l}\text { Abbandonare immediatamente la zona minacciata d'inondazione: } \\
\text { attenersi alle comunicazioni o istruzioni locall impartite. }\end{array}$ \\
\hline $\begin{array}{l}\text { Ende der Gefahr: } \\
\text { Fin du danger: } \\
\text { Fine del pericolo: }\end{array}$ & $\begin{array}{l}\text { Bekanntgabe über Radio } \\
\text { Annonce par radio } \\
\text { Annunciata per radio }\end{array}$ \\
\hline $\begin{array}{l}\text { Weitere Sirenenzeichen und Anweisungen der Kantone un } \\
\text { sonderes Merkblatt erlassen. } \\
\text { D'autres signaux et instructions émis par les cantons et les } \\
\text { pour le service actif. } \\
\text { Restano riservati ulteriori segnali d'allarme e le istruzion } \\
\text { saranno pubblicate istruzioni particolari. }\end{array}$ & $\begin{array}{l}\text { dd Gemeinden bleiben vorbehalten. - Für den aktiven Dienst wird ein be- } \\
\text { s communes sont róservés. - Des instructions spéciales seront publiées } \\
\text { i complementari emanati dai cantoni e comuni. - Per il servizio attivo }\end{array}$ \\
\hline ZENTRALSTELIE FUR GESAMTVERTEIOIGUNG & UFFICIO CENTRALC OCLLA DIFESA \\
\hline
\end{tabular}

Abb. 24 Merkblatt für den Sirenenalarm, 1982. 
als Strahlenalarm interpretieren. Es galt, sich nun unverzüglich in den Schutzraum oder den Keller zu begeben und das Radio einzuschalten, um von den Behörden weitere Anweisungen zu empfangen. ${ }^{105}$ Der Landessender stand der Alarmorganisation inzwischen auch in der sendefreien Zeit zur Verfügung, und die Überwachungszentrale konnte sich jederzeit ins Radionetz einschalten und die laufenden Sendungen für Notfallmeldungen unterbrechen. ${ }^{106}$ Die zu Beginn der 198oer Jahre installierte Kombination von Sirene und Radio als Kern der schweizerischen Notfall-Kommunikation erwies sich als äußerst langlebig. Der jeweils am ersten Mittwoch des Monats Februar jährlich stattfindende gesamtschweizerische Sirenentest stellt insofern ein unüberhörbares medientechnisches Erbe des Kalten Krieges dar. ${ }^{107}$

Im bereits erwähnten Pressecommuniqué, welches die ZGV anlässlich der Publikation des Sirenen-Merkblattes in den Telefonbüchern publizierte, hieß es: „Potentielle Gefahren aus Natur und Technik sind heute vielfältig.“ Die Gesamtverteidigung müsse sich diesen verschiedenen Bedrohungen annehmen, da „diese ja nicht ausschliesslich auf einen Krieg ausgerichtet [ist], sondern ebenso sehr auf die Fälle der Krise und der Katastrophe. ${ }^{\text {108 }}$ Diese Aussage ist insofern bemerkenswert, als die ZGV auf die wahrgenommene Ausweitung von Bedrohungspotenzialen mit einer Ausdehnung des Wirkungskreises der Gesamtverteidigung reagierte. Die historische Forschung betont gemeinhin, der Fokus des Bevölkerungsschutzes habe sich erst ab Mitte der 198oer Jahre vom Bedrohungsbild des Atomkrieges auf dasjenige ziviler und Naturkatastrophen verschoben, was zum einen mit einer sich verstärkenden Zivilschutzkritik und zum anderen mit den Auswirkungen des Katastrophenjahrs 1986, also dem Reaktorunfall von Tschernobyl und dem Chemieunfall von Schweizerhalle, erklärt wird. ${ }^{109}$ Meine Ausführungen zeigen indessen, dass diese Verschiebung bereits in den 1970er Jahren einsetzte, als das ältere Bedrohungsbild eines Nuklearkrieges zunehmend von neueren Bedrohungsvorstellungen ziviler atomarer Katastrophen überlagert wurde. Dafür verantwortlich war keine Kritik an der bestehenden Konzeption des Zivilschutzes

\footnotetext{
105 Vgl. Merkblatt „Alarmierung der Bevölkerung in Friedenszeiten“, in: Brenner 1982, S. 26.

106 Vgl. CH-BAR\#E819oC\#1993/149\#49*, Protokoll der Informationstagung über die Alarmorganisation in der Umgebung der Kernkraftwerke, 4.1.1982.

107 Vgl. Der jährliche Sirenentest (Webseite).

108 CH-BAR\#E439oC\#1997/14\#223*, Pressecommuniqué betreffend Merkblatt für die Alarmierung der Bevölkerung, 1.9.1980.

109 Vgl. bspw. Meier/Meier 2010, S. 229-231; Meier M. 2007, S. 223 f. Vgl. zur Neuausrichtung des schweizerischen Zivilschutzes nach dem Kalten Krieg auch: Deville/Guggenheim 2015, bes. S. $288-295$.
} 
oder der Gesamtverteidigung, sondern die wahrgenommene Zunahme von Gefahren und Risiken im nuklearen Alltag.

\section{(De-)Zentralismus und Notfallföderalismus}

Es dürfte inzwischen klar geworden sein, dass es enormer Anstrengungen bedurfte, um während des Alarmierungsprozesses einen reibungslosen Informationsfluss sicherzustellen. Die Alarmorganisation basierte auf der zentralen Leitung durch den Alarmausschuss, welcher den Notfalleinsatz von der Alarmzentrale heraus koordinierte. Auf Abb. 23 ist gut ersichtlich, dass die Alarmzentrale als Kommandoraum fungierte und das Zentrum der Alarmorganisation bildete. Sämtliche Informationen flossen hier zusammen, alle Maßnahmen und Weisungen hatten hier ihren Ursprung. Bereits zu Beginn der 1970er Jahre, als die erste Aufbauphase der Alarmorganisation vor dem Abschluss stand, betonte der Alarmausschuss indessen, es sei „kaum denkbar, dass sich die Schutzmassnahmen in einer Katastrophensituation allein zentral steuern lassen." Vielmehr brauche es neben dem Alarmausschuss „regional, kantonal und lokal kompetente Instanzen, die auch bei einem Ausfall von Kommunikationsmitteln selbständig vorgehen können.“110 „Das Endziel einer Alarmorganisation muss deshalb sein“ - so der Alarmausschuss weiter -, ,dass in den ersten Phasen der Bedrohung jede Gemeinde in der Lage sein muss die Situation einzuschätzen und erste Sofortmassnahmen zu treffen [...]. ${ }^{“ 11}$ Die politische Herausforderung des Alarmierungsdispositivs bestand somit darin, die föderalen Strukturen der Schweiz derart zu nutzen, dass die preparedness der Alarmorganisation auch bei gestörter Kommunikation gewährleistet wäre.

Mit Blick auf die US-amerikanische Zivilverteidigung haben die beiden Sozialanthropologen Stephen Collier und Andrew Lakoff den Begriff der "distributed preparedness" geprägt. Gemeint ist damit eine Organisations- und Planungsform, bei welcher die Verantwortung, sich auf unkalkulierbare, aber potenziell katastrophale Ereignisse vorzubereiten bzw. diese Vorbereitung zu planen, auf unterschiedliche Regierungsebenen verteilt wird. Eine spezifische Dimension dieser "distributed preparedness“ stellt der "emergency federalism“ dar, welcher darauf abzielt, die Maßnahmen der lokalen, staatlichen und bundesstaatlichen Behörden zu koordinieren. Dabei steht in normalen Zeiten die gemeinsame Planung im Vordergrund, während in Notfällen eine geeinte

110 CH-BAR\#E330oC\#1993/155\#594*, Überblick über die vorauszusehenden und durchzuführenden Massnahmen gegen die radioaktive Gefährdung im Falle einer Atombombenkatastrophe in Friedenszeiten (Entwurf), 4.11.1971.

111 Archiv BAG, 18.10.57a, Alarmzentrale, Überblick über die vorauszusehenden und durchzuführenden Massnahmen gegen die radioaktive Gefährdung im Falle einer AtombombenKatastrophe in Friedenszeiten, 6.4.1971. 
Führungsstruktur zum Einsatz gelangen soll.112 Das vom Alarmausschuss subsidiär und föderalistisch geplante Notfallmanagement der Alarmorganisation lässt sich, wie sich im Folgenden zeigen wird, als schweizerischer „emergency federalism" bezeichnen.

In seinem Bericht über die Sicherheitspolitik der Schweiz aus dem Jahr 1973 zählte der Bundesrat den AC-Schutz zu denjenigen Maßnahmen, die „im Zeitalter der umfassenden Bedrohung notwendig und von strategischer Bedeutung" seien. ${ }^{113}$ Der ebenfalls 1973 geschaffene Ausschuss AC-Schutz des Stabes für Gesamtverteidigung, der wie erwähnt personell mit dem Alarmausschuss praktisch identisch war, erarbeitete in den folgenden Jahren ein Konzept für einen Koordinierten AC-Schutzdienst. Als Ergänzung der Alarmorganisation auf der Ebene der Kantone und Gemeinden konzipiert, sollte der Koordinierte AC-Schutzdienst die Zusammenarbeit zwischen den Bundes-, Kantons- und Gemeindebehörden im Bereich von Atomalarm und Strahlenschutz stärken. Da der Strahlenschutz grundsätzlich eine Bundesaufgabe darstellte, setzte das schließlich 1981 vom Bundesrat genehmigte Konzept des Koordinierten ACSchutzdienstes stark auf die Initiative der einzelnen Kantone und Gemeinden.

$\mathrm{Zu}$ Beginn der 198oer Jahre verfügten sämtliche Kantone über zivile Führungsstäbe und für Zeiten aktiven Dienstes über eine Leitungsorganisation der Gesamtverteidigung. Gemäß dem Konzept des Koordinierten ACSchutzdienstes sollten die Kantone einen Chef für den AC-Schutzdienst ernennen. Diesen kantonalen AC-Schutzdienstchefs kam in erster Linie eine Koordinationsfunktion auf Kantonsebene zu. So sollten sie unter anderem einen kantonalen Notfallplan erstellen, eine Alarmstelle schaffen und die Zusammenarbeit mit den Atomwarnposten, dem AC-Schutzdienst von Zivilschutz und Armee, dem kantonalen Labor, den AC-Laboratorien der Armee und weiteren Stellen regeln. ${ }^{114}$

Bei den Gemeinden war der Aufbau kommunaler Führungsorgane Anfang der 198oer Jahre unterschiedlich weit fortgeschritten. In der Regel verfügten sie in der örtlichen Schutzorganisation des Zivilschutzes über einen Dienstchef AC-Schutzdienst. Größere Gemeinden hatten neben dem Zivilschutz auch bei der Polizei und den Feuerwehren Personal, das Strahlenschutzkurse absolviert hatte und Strahlenspürgeräte bedienen konnte. Das Konzept des Koordinierten AC-Schutzdienstes sah nun vor, die örtlichen AC-Schutzdienstchefs in die

112 Vgl. Collier/Lakoff 2008a; Collier/Lakoff 2008b. Vgl. auch Kaufmann 2011; Collier/Lakoff 2009; Collier/Lakoff 2008c; Dunn Cavelty 2008; Collier/Lakoff 2006.

113 Bundesrat 1973, S. 141, Hervorh. i. Orig.

114 Vgl. CH-BAR\#E330oC\#1996/29o\#517*, Konzept des Koordinierten AC-Schutzdienstes, 19.2.1981. 
Führungsorgane der Gemeinden zu integrieren. Dort kam ihnen die Aufgabe zu, die kommunalen Führungsorgane in AC-Fragen zu beraten und im Fall einer Alarmierung den kommunalen Notfallplan einzuleiten und durchzuführen. Dieser Notfallplan sollte als wesentliche Punkte unter anderem das Betreiben einer Alarmstelle, die Warnung und Alarmierung der Bevölkerung, die Verhinderung eines Verkehrschaos, das Aufbieten von Zivilschutzeinheiten zur Sicherstellung des Schutzraumbezuges, der Strahlenmessung und des Sanitätsdienstes, den Notbetrieb von Elektrizitäts-, Wasser- und Gasanlagen sowie das Bereitstellen von Mitteln für Personentransporte umfassen. ${ }^{115}$

Zum einen bedingte das Konzept des Koordinierten AC-Schutzdienstes enorme Anstrengungen hinsichtlich der Ausbildung von AC-Spezialisten für die Kantone und die Gemeinden. Eine „einheitliche Information und Ausbildung“ - so war im Konzept zu lesen - sei von "besonderer Bedeutung“.116 Der Bund verstärkte deshalb ab Mitte der 1970er Jahre die Ausbildungsmöglichkeiten im Bereich des AC-Schutzes, wobei er mit dem Bau des nationalen Ausbildungszentrums des AC-Schutzdienstes in Spiez, das 1977 den Betrieb aufnahm, - wie im Konzept nicht ohne Stolz festgehalten war - „günstige Voraussetzungen für die Ausbildung" schuf. ${ }^{117}$ So führte die Abteilung ACSchutzdienst, bisweilen gemeinsam mit der ZGV oder Zivilschutzvertretern, verschiedene Fach- und Ausbildungskurse durch, die sich an die Chefs der kantonalen AC-Schutzdienste und Zivilschutzämter, die Mitglieder der kantonalen Führungsstäbe, die Chefs des AC-Schutzdienstes der Territorialorganisation der Armee, das Personal der Labororganisation der Armee, an die die Atomwarnposten des Alarmausschusses bedienenden Polizeikräfte sowie die Dienst- und Gruppenchefs des AC-Schutzdienstes der örtlichen Schutzorganisationen richteten. Daneben bildete die Schule für Strahlenschutz des Eidgenössischen Institutes für Reaktorforschung in Würenlingen Strahlenschutzexperten für die Polizei und die Feuerwehr aus. ${ }^{118}$

Zum anderen setzte das Konzept des Koordinierten AC-Schutzdienstes komplexe Koordinationsleistungen zwischen den Strahlenschutzorganen von Bund, Kantonen und Gemeinden voraus. Je nach Bedrohungsstufe waren unterschiedliche Kooperationen zwischen kommunalen, kantonalen und nationalen Strahlenschutzorganen vorgesehen. Wären aufgrund eines Transport- oder Betriebsunfalls mit radioaktiven Stoffen lokal eingegrenzt nur

\footnotetext{
115 Vgl. ebd.

116 Ebd.

117 Ebd. Dem Bau des AC Labors in Spiez war in den 195oer und 196oer Jahren ein gescheitertes Bauprojekt in Wimmis vorausgegangen. Vgl. dazu Hug 1997, S. 96 f.

118 Vgl. ebd.
} 
wenige Personen gefährdet - dies entsprach der Bedrohungsstufe eins -, so würde die Führung der betroffenen Gemeinde obliegen. Diese müsste in erster Linie mit denjenigen Instanzen zusammenarbeiten, welche die betroffenen Betriebe auch im Normalfall kontrollierten, das heißt entweder mit dem Bundesamt für Gesundheitswesen, der Schweizerischen Unfallversicherungsanstalt oder der Abteilung für die Sicherheit der Kernanlagen. ${ }^{119}$ Bei Bedrohungsstufe zwei - einer regionalen Gefährdung von Menschen, ausgelöst durch einen Reaktorunfall - müsste die Führung an den Kanton übergehen. Zusätzlich zu den Maßnahmen der Bedrohungsstufe eins würden nun auch die Mittel des Kantons und des Alarmausschusses Verwendung finden. Bei Bedrohungsstufe drei - verursacht durch eine Nuklearexplosion mit radioaktiver Verstrahlung, welche die Bevölkerung ganzer Landesteile gefährdete - käme das zu Beginn dieses Teilkapitels beschriebene Alarmierungsdispositiv unter der Führung des Alarmausschusses zum Einsatz. ${ }^{120}$

Das Beispiel des Koordinierten AC-Schutzdienstes verdeutlicht eindrücklich die Expansionslogik der schweizerischen Gesamtverteidigung während des Kalten Krieges. Das Konzept des Koordinierten AC-Schutzdienstes führte zu einer enormen Vervielfachung von Strahlenalarm- und Strahlenschutzorganen. Die Alarmorganisation des Bundes wurde auf die Kantons- und Gemeindeebene ausgeweitet und dabei ausdifferenziert: Sämtliche Kantone und jede einzelne Gemeinde sollten über eigene Strahlenschutzspezialisten verfügen. So entstand ein zentral steuerbarer, gleichzeitig föderalistisch und subsidiär aufgebauter Strahlenschutz, bei dem die Organe auf Bundes-, Kantons- und Gemeindeebene sowohl in Kooperation miteinander als auch autonom voneinander einsetzbar sein sollten.

Neben diesen amtlichen Organen und Behörden existierten weitere Institutionen, die ihre Ressourcen in den Dienst der Alarmorganisation stellten. Die Schweizerischen Bundesbahnen würden bei einem atomaren Notfall den Zugverkehr rund um das gefährdete Gebiet koordinieren und insbesondere Zugsperren und Fluchtrouten organisieren. Die schweizerischen Post-, Telefon- und Telegrafenbetriebe wären für Maßnahmen zur Aufrechterhaltung der Fernmeldeverbindungen und des Radios verantwortlich. ${ }^{121}$ Die Nachrichten- und Sendenetze der Schweizerischen Depeschenagentur und der Schweizerischen Rundspruchgesellschaft kämen bei der Warnung und

119 Vgl. dazu Kapitel 4.1 und 4.2.

120 Vgl. CH-BAR\#E330oC\#1996/290\#517*, Konzept des Koordinierten AC-Schutzdienstes, 19.2.1981.

121 Vgl. CH-BAR\#E439oC\#1997/14\#223*, Massnahmen der Industriebetriebe bei gefährlich erhöhter Radioaktivität, in: Zivilschutz 1979, Nr. 11/12. 
Alarmierung der Bevölkerung zum Einsatz. Auch private Firmen fungierten als Teile des Alarmierungsdispositivs. So forderte die ZGV große Industriebetriebe dazu auf, bei ihrem Werk- oder Betriebsschutz eine Alarmstelle zu bezeichnen, einen Krisenstab einzurichten, für erhöhte Radioaktivität einen Notfallplan auszuarbeiten und diese Maßnahmen mit denjenigen der entsprechenden Gemeinden zu koordinieren. ${ }^{122}$ Die Expansionsdynamik des Alarmierungsdispositivs fand ihren Ausdruck somit auch in der erfolgreichen Mobilisierung und Einbindung bedeutender Institutionen und Unternehmen. In den „emergency federalism“ der Alarmorganisation waren schließlich eine Vielzahl privater und staatlicher Akteure sämtlicher föderaler Ebenen eingebunden.

Der schweizerische Notfallföderalismus funktionierte jedoch nicht wie geplant. Dies wurde insbesondere anlässlich des Kernkraftwerkunfalls in Harrisburg im März 1979 evident. Die Geschäftsprüfungskommission des Nationalrates nahm diesen Störfall zum Anlass, sich über den Stand der Sicherheitsvorkehrungen der schweizerischen Kernkraftwerke zu informieren. In ihrem Bericht an den Bundesrat vom November 1980 gelangte sie zwar zu dem Schluss, dass "die Alarmorganisation bereits weitgehend ausgebildet" sei. „Der praktische Katastrophenschutz der Bevölkerung umfasst aber“ - so der Bericht weiter - „neben der Alarmierung vor allem die Massnahmen der kantonalen und Gemeindebehörden auf dem Gebiet der Polizei, der Feuerwehr und des Zivilschutzes und setzt voraus, dass die Bevölkerung richtig reagiert. Dieses Zusammenspiel ist heute noch nicht genügend gesichert.“123 Das auf "distributed preparedness“ ausgerichtete Dispositiv der Alarmorganisation trug zwar den föderalistisch-subsidiären Prinzipien der Schweiz Rechnung, stellte die Vielzahl der involvierten Personen und Organisationen aber vor große Koordinations- und Kooperationsherausforderungen. Die Geschäftsprüfungskommission des Nationalrates empfahl dem Bundesrat deshalb, den Katastrophenschutz für den Fall von Kernkraftwerkunfällen auf allen föderalen Ebenen unter Einbezug der Bevölkerung vermehrt einzuüben. ${ }^{124}$

\footnotetext{
122 Vgl. ebd., und Schreiben des Direktors der ZGV (2. Entwurf), 27.8.1980.

123 CH-BAR\#E330oC\#1996/29o\#567*, Bericht der Arbeitsgruppe der Geschäftsprüfungskommission zur Frage der Sicherheit der Kernkraftwerke, 14.11.1980.

124 Vgl. ebd.
} 


\section{Kombinierung und Computerisierung in der nationalen Alarmzentrale}

Die Überprüfung der Alarmorganisation im Zuge des Kernkraftwerkunfalls von Harrisburg bildete indessen nicht den einzigen Anlass, an dem gegen Ende der 1970er Jahre Koordinationsdefizite beim Strahlenalarm festgestellt wurden. Vielmehr traten diese auch an den Gesamtverteidigungsübungen 1977 und 1980 deutlich zutage. Nach beiden Übungen räumten die Auswertungsberichte dem Problembereich der Warnung, Alarmierung und Informierung der Bevölkerung bei Katastrophen erste Priorität ein. ${ }^{125}$ Der Bundesrat beauftragte die Leitungsorganisation für Gesamtverteidigung mit der Lösung dieses Problemkreises. Die bereits erwähnte, vom Stab für Gesamtverteidigung nach der Gesamtverteidigungsübung 1977 eingesetzte Studiengruppe Warnung und Alarmierung erarbeitete daraufhin ein Konzept, welches die Errichtung einer Nationalen Alarmzentrale vorsah. ${ }^{126}$ Die Schaffung der Nationalen Alarmzentrale verdeutlicht einmal mehr, wie Erkenntnisse aus nationalen Verteidigungsübungen als Katalysatoren fungierten, um die Notwendigkeit von Projekten der Gesamtverteidigung zu begründen und zu legitimieren. ${ }^{127}$

Die Nationale Alarmzentrale wurde als Gemeinschaftsprojekt von Alarmausschuss und Militär realisiert. Bereits ab Mitte der 1970er Jahre plante das EDI einen Erweiterungsbau bei der Schweizerischen Meteorologischen Zentralanstalt, mit welchem unter anderem die Verlegung der lediglich provisorischen Alarmzentrale des Alarmausschusses aus Bern nach Zürich und deren Zusammenführung mit der Überwachungszentrale, die dort seit 1975 untergebracht war, verwirklicht werden sollte. Zur gleichen Zeit meldete das Eidgenössische Militärdepartement Baubedürfnisse für verschiedene in Zürich installierte militärische Überwachungs- und Übermittlungsanlagen an und schlug in diesem Zusammenhang eine gemeinsame Projektierung vor. In der Folge wurde bei der Meteorologischen Zentralanstalt eine kombinierte Anlage für den Alarmausschuss und das Militär erstellt. ${ }^{128}$

125 Vgl. CH-BAR\#E568oC\#1998/161\#122*, Beilage 1 des Berichts über den Stand Ende 1979 der Auswertung der Gesamtverteidigungsübung 1977, ohne Datum, und Beilage 2 des Berichts über den Stand Ende 1979 der Auswertung der Gesamtverteidigungsübung 1977 (2. Teil), ohne Datum; CH-BAR\#E568oC\#1998/161\#119*, Beschlussprotokoll Sitzung Stab GV vom 22.1.80, 1145 (5.2.80), 22.1.1980. Vgl. dazu auch Kapitel 5.2 und 5.3.

126 Vgl. CH-BAR\#E439oC\#1997/14\#226*, Antrag des EDI, 6.6.1983.

127 Vgl. dazu Kapitel 5.

128 Vgl. CH-BAR\#E3300C\#1996/289\#574*, Antrag des EDI, 1.12.1978. Vor dem Hintergrund der angespannten Finanzlage des Bundes zu dieser Zeit kam die gemeinsame Anlage nicht zuletzt „aus Wirtschaftlichkeits- und Zweckmässigkeitsgründen“ zustande. 
Die örtliche Zusammenlegung von zivilen und militärischen Warn- und Alarmierungsnetzen hatte neben finanziellen und baulichen Synergien den zusätzlichen Vorteil, dass dadurch - so ein internes Papier - insbesondere beim Übergang vom Friedens- in den Kriegszustand eine „entscheidende Erhöhung der Funktionssicherheit" erreicht werden könne. ${ }^{229}$ Die Kombination von zivilen und militärischen Überwachungs- und Alarmierungsnetzen in der Nationalen Alarmzentrale bot damit eine Lösung für ein Problem, auf welches die Mitglieder der KUeR bereits Ende der 195oer Jahre zum ersten Mal hingewiesen hatten.

Die Nationale Alarmzentrale nahm ihren Betrieb im Herbst 1984 auf. Für AC-Belange oblag die Leitung der vom Bundesrat neu eingesetzten Eidgenössischen Kommission für AC-Schutz. Diese war dem EDI unterstellt und übernahm die Aufgaben des Ausschusses AC-Schutz des Stabes für Gesamtverteidigung und des Alarmausschusses der KUeR, die beide Ende 1984 aufgelöst wurden. ${ }^{130}$ In einer ersten Phase sollte die Nationale Alarmzentrale Bedrohungen durch Radioaktivität - etwa ausgelöst durch Atomexplosionen, Kernkraftwerkunfälle, Transportunfälle oder Industrieunfälle -, Bedrohungen durch Überflutungen - insbesondere infolge von Talsperrenbrüchen - sowie Bedrohungen durch Satellitenabstürze abdecken. In einer zweiten Phase ab 1990 sollte die Nationale Alarmzentrale zusätzlich auch Luftbedrohungen infolge strategischer Überfälle, chemische Bedrohungen, biologische Bedrohungen und Bedrohungen durch Naturkatastrophen überwachen. ${ }^{131}$ Daten über all diese Bedrohungsarten wurden im Kernstück der Nationalen Alarmzentrale - der Anlage „Metalert“ - zentral gesammelt und ausgewertet.

Die Anlage "Metalert" stellte - wie der Name schon andeutet - eine Kombination aus meteorologischer Anstalt und Alarmierungszentrale dar. ${ }^{132}$ In ihr flossen die Daten verschiedener ziviler und militärischer Sensornetze zusammen. Dazu zählten unter anderem das automatische Beobachtungsnetz zur landesweiten Erfassung der Wetterdaten ANETZ der Schweizerischen Meteorologischen Anstalt, das Netz für Automatische Dosis-Alarmierung

129 CH-BAR\#E439oC\#1997/14\#223*, Bedürfnisnachweis des Alarmausschusses der KUeR, 8.6.1979.

130 Vgl. CH-BAR\#E439oC\#1997/14\#224*, Ausschuss AC-Schutz des Stabes GV ab 1.1.85 (Neustrukturierung), ohne Datum, und Verordnung über die Nationale Alarmzentrale, 31.10.1984.

131 Vgl. CH-BAR\#E439oC\#1997/14\#226*, Konzept Nationale Alarmzentrale in der Anlage Metalert, 1.10.1982.

132 Vgl. ebd., Auszug aus dem Amtlichen Bulletin, 81.082, Meteorologische Anstalt (METALERT II), 23.9.1982. 
und -Messung NADAM des Alarmausschusses sowie die Überwachungs-, Vorhersage- und Auswerteanlage "Gammaflinte“ des Militärdepartements, die mittels eines Netzes von seismischen Sensoren, Radarstationen und Empfängern für elektromagnetische Impulse Kernexplosionen erfassen, Ausfallprognosen ermitteln und Verstrahlungskarten ausarbeiten konnte. ${ }^{133}$ Die zentrale Datensammlung und -auswertung in „Metalert" sollte „die laufende Überwachung und rasche Feststellung aussergewöhnlicher radiologischer Ereignisse" ermöglichen. ${ }^{134}$

In der Nationalen Alarmzentrale spiegelte sich der medientechnische Wandel der 1980er gegenüber den 1970er Jahren wider, dessen Schlüsselbegriff Computerisierung lautete. ${ }^{135}$ Dies lässt sich anhand eines Beispiels aus dem Bereich der Radioaktivitätsmessung illustrieren. Das NADAM des Alarmausschusses ging im Juni 1982 mit acht Pilotstationen in den Versuchsbetrieb. Beim Endausbau sollte das NADAM über 51 über die Schweiz verteilte automatische Messstationen verfügen, welche sich bei den Standorten des ANETZ der Schweizerischen Meteorologischen Anstalt befanden. Die Registrierung und Übermittlung der Ortdosisleistung durch die NADAM-Sonden erfolgte im Echtzeitverfahren alle zehn Minuten. ${ }^{136}$ Während zu Beginn der 1970er Jahre die Filter der Frühwarnposten zur Analyse ins Labor der KUeR nach Fribourg gesendet werden mussten, erfolgten Radioaktivitätsmessungen mit den NADAM-Sonden nun an Ort und Stelle. Eine gefährliche Erhöhung der Radioaktivität musste also nicht mehr relativ aufwändig im Feld gemessen und einem Labor übermittelt werden, sondern ließ sich über Sonden automatisch registrieren und verfolgen. Somit wurden - mit Bruno Latour gesprochen - an zentralen Stellen menschliche durch nicht-menschliche Aktanten ersetzt. ${ }^{137}$ Gleichzeitig stellte die Computerisierung des Strahlenalarms neue Anforderungen hinsichtlich der Kompatibilität und Integration von Daten aus unterschiedlichen Systemen.

133 Vgl. CH-BAR\#E 3300 \#\#1996/291\#688*, Militärisches Pflichtenheft für die Ueberwachungs-, Vorhersage- und Auswerteanlage 82 für Kernexplosionen, 10.7.1979.

134 CH-BAR\#E330oC\#1996/289\#575*, Botschaft über den Bau einer kombinierten Anlage bei der Schweizerischen Meteorologischen Anstalt, 15.8.1979. Vgl. auch CH-BAR\#E439oC \#1997/14\#223* , Bedürfnisnachweis des Alarmausschusses der KUeR, 8.6.1979.

135 Zur Computerisierung: Gugerli 2018; Bösch 2018. In der Schweiz: Bächi 2002; Gugerli 2001; Museum für Kommunikation 2001.

136 Vgl. CH-BAR\#E439oC\#1997/14\#224*, NADAM, ein landesweites Netz für die automatische Fernmessung der Ortsdosisleistung in der Schweiz, Oktober 1982; CH-BAR\#E330oC \#1996/214\#718*, Verarbeitung der Messdaten aus dem Netz für Automatischen DosisAlarm und Messung (Entwurf), 21.5.1979. Inzwischen wurde das NADAM auf 76 Stationen ausgebaut. Vgl. Messnetze (Webseite).

Vgl. Latour 2008 [1991]. 
In der Nationalen Alarmzentrale lag das Hauptgewicht auf zivilen Gefahren atomarer und anderer Art. Kernexplosionen, wie sie die militärische Überwachungs-, Vorhersage- und Auswerteanlage „Gammaflinte“ detektieren konnte, bildeten nur noch eine von vielen möglichen Bedrohungsformen. Triebkraft für diese Entwicklung - so zeigt das nächste Teilkapitel nochmals deutlich - bildete die wahrgenommene Zunahme von zivilen nuklearen Bedrohungspotenzialen, die sich ab Mitte der 1970er Jahre im Bedrohungsbild des Kernkraftwerk-, Transport- oder Industrieunfalls verdichteten.

\subsection{Politische Rücksichtnahmen und ,unsicheres' Wissen. Schaffung eines Alarmsystems für Kernkraftwerke, 1974-1983}

Zu Beginn der 1970er Jahre verlagerte die Eidgenössische Kommission zur Überwachung der Radioaktivität (KUeR) ihre Tätigkeit immer mehr auf die Überwachung von Atomanlagen und anderen Betrieben, die im nuklearen Alltag mit Strahlen und radioaktiven Stoffen operierten. ${ }^{138}$ In diesem Zusammenhang beschloss die KUeR 1974, ein spezielles Warnsystem für die Umgebung von Kernkraftwerken zu fordern. Wie Professor Otto Huber - in Personalunion sowohl Präsident der KUeR als auch des Alarmausschusses - erläuterte, war ein derartiges Alarmsystem „notwendig zur Deckung der Strahlenrisiken in den ersten Stunden nach einem Unfall“. Die bestehende Alarmierungsmöglichkeit über die Überwachungszentrale des Alarmausschusses sei dazu „zu langsam und daher unbefriedigend“. ${ }^{139}$ Um die preparedness der Alarmorganisation auch für mögliche Atomkraftwerkunfälle herzustellen, plädierte Huber für den Aufbau eines Alarmsystems mit automatisch auslösbaren Sirenen. Der Alarmausschuss entschied sich daraufhin, die Idee eines raschen Alarmsystems in der Nähe von Kernkraftwerken weiterzuverfolgen. Einzelne Mitglieder begrüßten dabei nicht zuletzt "den günstigen psychologischen Effekt eines Warnsystems auf die Bevölkerung". ${ }^{140}$

Der Aufbau eines speziellen Alarmsystems in der Umgebung von Atomkraftwerken steht im Zentrum dieses Teilkapitels. Mit den Sichtweisen der verschiedenen involvierten Bundesstellen sowie der betroffenen Kantone und der Kernkraftwerkbetreiber untersuche ich dabei zum einen die mit dem Alarmsystem verbundenen politischen Implikationen. Diese waren - was im

\footnotetext{
138 Vgl. dazu Kapitel 3.3.

139 Archiv BAG, 18.2.63, Ausschuss AC-Schutz des Stabes ZGV, Protokoll der 33. Sitzung des Alarmausschusses und des Ausschusses AC-Schutz, 22.3.1974.

140 Ebd.
} 
Zitat über den „psychologischen Effekt“ auf die Bevölkerung schon anklang wesentlich von den gesellschaftlichen Auseinandersetzungen um die zivile Nutzung der Atomenergie geprägt, die sich in den 1970er Jahren im Widerstand gegen den Bau eines Kernkraftwerks im aargauischen Kaiseraugst verdichteten. ${ }^{141}$ Zum anderen analysiere ich das Kernstück des geplanten Alarmsystems, nämlich die Einteilung der Umgebung der Atomkraftwerke in verschiedene Gefahrenzonen. Dabei wird sich zeigen, dass diese Zoneneinteilung auf Wissensbeständen und Normen basierte, die in verschiedenerlei Hinsicht als ,unsicher - ich werde auf diesen Begriff zurückkommen - bezeichnet werden können.

\section{Synergieeffekte, Lernprozesse und Wirtschaftsinteressen}

Die KUeR und der Alarmausschuss konnten nicht allein über den Aufbau eines raschen Alarmsystems für die Umgebung von Kernkraftwerken entscheiden. Insbesondere bedurfte es der Zustimmung des Eidgenössischen Amtes für Energiewirtschaft (AEW), welches unter anderem für die Durchführung der Bewilligungsverfahren für Atomanlagen sowie für die Aufsicht über diese verantwortlich war. ${ }^{142}$ Im April 1974 wandte sich Otto Huber deshalb mit einem Schreiben an AEW-Direktor Hans Rudolf Siegrist. Darin forderte er das AEW dazu auf, „die Einrichtung eines raschen zweckmässigen Alarmierungssystems für die Bevölkerung der Umgebung, mit einem der Wahrscheinlichkeit des Ereignisses angemessenen Aufwand, zu veranlassen. ${ }^{143}$ In seinem Antwortschreiben von Ende Juni 1974 hielt das AEW fest, es sei "prinzipiell bereit“, die Forderung nach einem raschen Alarmsystem „in Form einer Auflage an die KKW [Kernkraftwerke] weiterzuleiten“. Man wolle das Problem ,jedoch etwas klarer sehen“ und habe deshalb veranlasst, „dass eine ,feasibility study“ unternommen wird." ${ }^{144}$ Das AEW wollte also zuerst die Machbarkeit des geforderten Alarmsystems und den dafür notwendigen Aufwand abklären.

Noch vor Abschluss der vom AEW in Auftrag gegebenen Studie hielt der Alarmausschuss Besprechungen mit Regierungs- und Behördenvertretern des Kantons Aargau ab. Als Standortkanton einer Atomanlage und zweier Kernkraftwerke (ein drittes Atomkraftwerk befand sich im Bau) sowie als Austragungsort der Kontroverse um das geplante Kernkraftwerk Kaiseraugst war der Kanton Aargau Mitte der 1970er Jahre - wie andere Standortkantone

\footnotetext{
141 Zur Anti-Atomkraft-Debatte in der Schweiz vgl. Kapitel 1, Fn. 51.

142 Vgl. dazu Kapitel 3.3.

143 CH-BAR\#E330oC\#1993/155\#594*, Schreiben von O. Huber an H. R. Siegrist, 4.4.1974.

144 Archiv BAG, 18.6.1, Eidg. Kommission zur Überwachung der Radioaktivität KUeR, 5. Teil, Schreiben von C. Zangger an O. Huber, 27.6.1974.
} 
auch - besonders auf von Atomkraftwerken ausgehende Gefahren sensibilisiert. Aus diesem Grund hatte er im Januar 1975 eine kantonale Katastrophenübung durchgeführt, anlässlich welcher ein Unfall im Kernkraftwerk Beznau simuliert worden war. ${ }^{145} \mathrm{Im}$ Austausch mit dem Alarmausschuss zeigte sich der Kanton Aargau nun - so fasste Otto Huber zusammen - „an der baldigen Funktionstüchtigkeit eines angemessenen Alarmsystems sehr interessiert". ${ }^{146}$ Der Alarmausschuss unterbreitete dem Eidgenössischen Departement des Innern (EDI) in der Folge einen Plan zur Realisierung eines provisorischen Alarmsystems für die Umgebung der Kernkraftwerke Beznau I und II. ${ }^{147}$

Dieses Vorpreschen des Alarmausschusses aktivierte das AEW und das Eidgenössische Gesundheitsamt (EGA), welchem der Alarmausschuss angegliedert war. Beide Ämter kamen überein, dass man im Moment nicht vorgreifen, sondern zunächst das Ergebnis der in Auftrag gegebenen Machbarkeitsstudie abwarten solle. Die „dadurch entstehende Zeitverzögerung [sei] in Anbetracht der geringen Unfallwahrscheinlichkeit durchaus tragbar". ${ }^{148}$ Aufgrund dessen teilte das EDI dem Alarmausschuss mit, dass - solange das Eidgenössische Verkehrs- und Energiewirtschaftsdepartement (EVED) nicht über Art und Umfang eines Alarmsystems entschieden habe -

uns weitere Bemühungen in dieser Sache als verfrüht [scheinen], insbesondere
der Einbezug lokaler Instanzen und Teile der Bevölkerung. Wenn sich bei-
spielsweise kein genügend zuverlässiges Alarmsystem mit vertretbarem Auf-
wand realisieren liesse und das EVED deshalb darauf verzichtet, würde man
[...] unnötigerweise Unsicherheit in den betroffenen Kreisen verbreiten. Im
Hinblick auf die Bemühungen des Bundesrates um eine Lösung des Problems
"Kaiseraugst“ ist es von besonderer Wichtigkeit, dass nicht durch übereilte
Aktionen die Unsicherheit der Bevölkerung vermehrt wird.149

Gemeinsam mit dem AEW setzte das EGA also auf eine bewusste Verzögerungstaktik. Gegenüber der KUeR und dem Alarmausschuss wurde diese abwartende Haltung mit politischen Rücksichtnahmen während der laufenden Anti-Atomkraft-Debatte gerechtfertigt.

\footnotetext{
145 Vgl. dazu Kapitel 5.2.

146 CH-BAR\#E33ooC\#1993/155\#647*, Schreiben von O. Huber an H. Hürlimann, 25·7.1975.

147 Vgl. ebd.

148 CH-BAR\#E330oC\#1993/155\#594*, Aktennotiz über eine Besprechung zum Thema Alarmsysteme KKW, 11.8.1975. Vgl. auch CH-BAR\#E330oC\#1993/155\#647*, Schreiben von U. Frey an H. Hürlimann, 30.7.1975.

149 CH-BAR\#E330oC\#1993/155\#647*, Schreiben des EDI an O. Huber, 9.9.1975. Vgl. auch CHBAR\#E330oC\#1993/155\#594*, Notiz an Herrn Direktor Frey, 12.8.1975.
} 
Ein maßgebender Grund dafür, dass das EGA die KUeR und den Alarmausschuss nicht vorbehaltlos unterstützte, lag jedoch auch darin, dass das EGA (neue) Kompetenzstreitigkeiten mit dem AEW verhindern wollte. In der ersten Hälfte der 1970er Jahre war es zwischen der KUeR und den beiden nuklearen Sicherheitsbehörden - der Sektion für Sicherheitsfragen von Atomanlagen bzw. später Abteilung für die Sicherheit der Kernanlagen (ASK) und der Eidgenössischen Kommission für die Sicherheit von Atomanlagen (KSA) -, welche dem AEW angehörten bzw. diesem angegliedert waren, nämlich zu langwierigen Konflikten bezüglich der Radioaktivitätsüberwachung in der Umgebung von Atomanlagen gekommen. ${ }^{150}$ Gegenüber dem Vorsteher des EDI, Bundesrat Hans Hürlimann, warnte der Direktor des EGA Ulrich Frey nun deshalb davor,

dass sich in zunehmenden Masse Akzentverschiebungen im Aktivitätsbereich der Kuer geltend machen, die zu Ueberlappungen mit dem AEW führen können. Die Kuer wurde seinerzeit ins Leben gerufen, um die Folgen der Kernexplosionen über unserem Land regelmässig zu überwachen [...]. Es stellt sich [...] die Frage, ob die Kuer in ihrer heutigen Konzeption noch gerechtfertigt ist. Die Problematik hat sich von den Testexplosionen viel mehr in Richtung Gefährdung durch landeseigene oder in Landesnähe gelegener Kernkraftwerke verlagert. Hierfür sind andere Stellen zuständig. ${ }^{151}$

Das EGA war Mitte der 1970er Jahre nicht die einzige Stelle in der Bundesverwaltung, welche die Daseinsberechtigung der KUeR infrage stellte. Allerdings war all diesen Stellen bewusst, dass es angesichts der laufenden Auseinandersetzungen um die zivile Nutzung der Atomenergie, während derer sich die KUeR gegenüber der schweizerischen Öffentlichkeit als von der Verwaltung unabhängige und auf Transparenz bedachte Radioaktivitäts-Überwachungsstelle präsentierte, absolut nicht opportun war, solche Überlegungen öffentlich zu äußern. 152

Im Hinblick auf das geplante rasche Alarmsystem in der Nähe von Kernkraftwerken ergaben sich indessen vorerst keine Kompetenzprobleme. Im September 1975 wurden die Ergebnisse der vom AEW bei der ASK und der Elektrowatt Ingenieurunternehmung in Auftrag gegebenen Studie über die Realisierbarkeit von automatischen Alarmsystemen für die Bevölkerung in der Umgebung von Kernkraftwerken den interessierten und betroffenen Stellen

\footnotetext{
15 O Vgl. dazu Kapitel 3.3.

151 CH-BAR\#E330oC\#1993/155\#594*, Aktennotiz über die Besprechung mit Herrn BR Hürlimann, 15.9.1975.

$15^{2}$ Vgl. dazu Kapitel 3.3.
} 
an einem Seminar vorgestellt. ${ }^{153}$ Die Studie hielt als wichtigstes Ergebnis fest, „dass ein Alarmsystem für die Umgebung von Kernkraftwerken mit einem vernünftigen Aufwand realisiert werden kann [...].“154

Nachdem die Resultate dieser Studie vorlagen, empfahl zunächst die Sektion für Personen- und Umgebungsschutz der ASK dem AEW, von den Atomanlagen die Errichtung eines raschen Alarmsystems zu verlangen. ${ }^{155}$ Später gelangte die vom AEW zu einer Stellungnahme aufgeforderte KSA zum selben Schluss. ${ }^{156}$ In der Folge wurde von der ASK und dem Alarmausschuss gemeinsam ein Dokument mit dem Titel „Notfallplanung für die Umgebung von Kernkraftwerken“ erarbeitet. Dieses Dokument lag im Mai 1977 vor und sollte den an der Notfallplanung beteiligten Stellen - neben den involvierten Bundesstellen waren dies die betroffenen Kantone und Gemeinden sowie die Kernkraftwerkbetreiber - den Rahmen für die Realisierung eines raschen Alarmsystems skizzieren. ${ }^{157}$

Im Juli 1977 fand unter der Leitung des Vorstehers des EVED, Bundesrat Willi Ritschard, eine Orientierung der betroffenen Kantone - die Standortkantone Bern, Solothurn und Aargau sowie die Anrainerkantone Zürich, Luzern, Fribourg, Basel-Stadt, Basel-Land, Waadt, Neuenburg und Genf - statt. Gegenüber diesen Kantonen erklärte Bundesrat Ritschard, dass „[a]ngesichts der Tatsachen, dass der Schutzraumbau weit fortgeschritten ist und dass zahlreiche Organe, wie örtliche Zivilschutzorganisationen, Feuerwehr und Polizei für einen Katastropheneinsatz bereitstehen“, die Umstände für die Realisierung eines raschen Alarmsystems "sehr geeignet seien“. ${ }^{158}$ Die betroffenen Kantone begrüßten es, dass der Bund die Initiative für die Notfallplanung in der Umgebung von Kernkraftwerken ergriff. ${ }^{159}$ Die Kantone, die in ihrem Regierungsgebiet für die Sicherstellung der Notfallbereitschaft verantwortlich waren, ${ }^{160}$

153 Vgl. CH-BAR\#E33OoC\#1993/155\#647*, Realisierbarkeit von automatischen Alarmsystemen für die Bevölkerung in der Umgebung von Kernkraftwerken, 19.9.1975.

154 CH-BAR\#E439oC\#1997/14\#230*, Stand der Realisierung im August 1978, 7.8.1978.

155 Vgl. CH-BAR\# 3300 C\#1993/155 $\# 647^{*}$, Schreiben von W. Jeschki und S. Prêtre an W. Hunzinger, 27.9.1976.

156 Vgl. CH-BAR\#E819oC\#2003/447\#218*, Schreiben des Vorstehers des EVED an die Regierungen verschiedener Kantone, 31.5.1977.

157 Vgl. CH-BAR\#E330oC\#1993/155\#647*, Notfallplanung für die Umgebung von Kernkraftwerken, Mai 1977 .

158 CH-BAR\#E819oC\#2003/447\#218*, Schreiben des Vorstehers des EVED an die Regierungen verschiedener Kantone, 31.5.1977.

159 Vgl. ebd., Stellungnahme der Kantone zum Bericht „Notfallplanung für die Umgebung von Kernkraftwerken“, 5·4.1978.

16o Vgl. CH-BAR\#E819oC\#2003/447\#226*, A propos „Machbarkeit des Notfallschutzes“, 9.11.1982. 
waren augenscheinlich dankbar dafür, bei der Bewältigung dieser Aufgabe auf die Unterstützung und das Know-how von Bundesstellen zurückgreifen zu können.

Trotz anfänglichen (beabsichtigten) Verzögerungen - so lässt sich festhalten - stieß das Konzept eines raschen Alarmsystems für die Umgebung von Kernkraftwerken also bald auf relativ breite Unterstützung. Ein erster wesentlicher Grund dafür bestand darin, dass sich der Aufwand dafür in Grenzen hielt. Diesem Argument kam von Anfang an eine zentrale Bedeutung $\mathrm{zu}$, und es zog sich anschließend durch sämtliche positive Stellungnahmen. Bereits die KUeR und der Alarmausschuss hatten gefordert, das Alarmsystem solle „mit einem der Wahrscheinlichkeit des Ereignisses angemessenen Aufwand" errichtet werden. Die Machbarkeitsstudie bestätigte, dass das Alarmsystem „mit einem vernünftigen Aufwand realisiert werden“ könne und Bundesrat Ritschard versicherte den Kantonen, wichtige Komponenten des Alarmsystems wie die Schutzräume und die Zivilschutzorganisation seien schon vorhanden. Hinter der Frage der Machbarkeit stand also die Frage des Aufwandes, und hinter dieser wiederum ein Kosten-Nutzen-Kalkül, das sämtliche Projekte des Strahlenschutzes prägte. Die als positiv bewertete KostenNutzen-Bilanz führte dazu, dass auch Stellen wie die KSA, die an sich der Meinung waren, ein spezielles Alarmsystem für Kernkraftwerke sei aufgrund der bereits bestehenden hohen Sicherheitsanforderungen unnötig, sich nicht gegen dessen Errichtung wehrten. ${ }^{161}$ Anders formuliert könnte man auch sagen, dass beim Aufbau des raschen Alarmsystems in der Nähe von Kernkraftwerken Synergieeffekte genutzt werden konnten. Das ältere Bedrohungsbild des Nuklearkrieges hatte dazu geführt, dass die öffentliche Hand massiv in den Bau von Schutzräumen und den Ausbau der Zivilschutzinfrastruktur investiert hatte. Diese Investitionen ließen sich nun in den 1970er Jahren, als sich die wahrgenommene atomare Bedrohung auf den Zivilbereich ausweitete, gewissermaßen doppelt amortisieren.

Für die praktisch einhellige Zustimmung zum geforderten Alarmsystem gab es aber noch einen zweiten wichtigen Grund. Der Bund, der als Bewilligungsinstanz für Atomkraftwerke längst nicht mehr nur bei gewissen Teilen der Bevölkerung, sondern auch bei einigen der betroffenen Kantone massiv in der Kritikstand, ${ }^{162}$ wollte demonstrieren, dass man die vorhandenen Bedenken und Ängste ernst nahm. Tatsächlich machte der Bundesrat während der laufenden Anti-Atomkraft-Debatte verschiedene Versprechungen und Konzessionen.

161 Vgl. CH-BAR\#E330oC\#1993/155\#647*, Schreiben des EDI an O. Huber, 9.9.1975.

162 So insbesondere der Kanton Basel-Land. Vgl. dazu Kupper 2003a, S. 117 f. 
Dazu zählten insbesondere die Revision des Atomgesetzes, ${ }^{163}$ jedoch auch die Schaffung geeigneter Alarmierungsmöglichkeiten zum Schutz der Bevölkerung in der Umgebung der Kernkraftwerke, auf die auch in offiziellen Antworten des Bundesrates auf Vorstöße von Parlamentsmitgliedern verwiesen wurde. ${ }^{164}$ Der Errichtung von speziellen Alarmsystemen für Atomkraftwerke kam folglich auch eine politisch-strategische Komponente zu. Dies umso mehr, weil sich gleichzeitig ein Wandel in der Informationspolitik vollzog. Exemplarisch lässt sich dies anhand einer Ansprache von Bundesrat Willi Ritschard zeigen, die dieser anlässlich der Orientierung der Kantone über die Notfallplanung für die Umgebung von Kernkraftwerken im Juli 1977 hielt. Dort betonte Ritschard, die schweizerische Öffentlichkeit müsse „rückhaltlos offen orientiert werden":

In der Vergangenheit hat man Dinge verharmlost; Dinge zu verharmlosen, die nicht harmlos sind, ist immer gefährlich. Das eben gesagte gilt auch für die Katastrophenpläne, die hier besprochen werden. Aus dem Dokument „Notfallplanung für die Umgebung von Kernkraftwerken“ ersieht man, dass sich der Bund schon lange mit Katastrophenplänen beschäftigt. Allerdings beschäftigte er sich damit sehr geheim. Das war eindeutig falsch. ${ }^{165}$

Dieses Plädoyer für Offenheit statt Geheimhaltung kann als das Ergebnis eines kollektiven Lernprozesses gedeutet werden. Damit verbunden war auch ein verändertes Gouvernementalitätsverständnis. Die Öffentlichkeitsarbeit sollte sich nun an den wahrgenommenen Informationsbedürfnissen orientieren und insofern nicht mehr, paternalistisch' oder ,autoritär', sondern eher ,liberal ${ }^{\text {t }}$ gehandhabt werden. ${ }^{166}$ Hinter dieser neuen Informationspolitik stand eine angepasste Form des Regierens von Strahlen, die Transparenz gegenüber der Öffentlichkeit als Ressource erkannte.

Ein dritter maßgebender Grund dafür, dass das rasche Alarmsystem auf recht großen Zuspruch stieß, bestand darin, dass das vorgesehene Konzept es ermöglichte, auf die finanziellen Interessen der Kernkraftwerkbetreiber Rücksicht zu nehmen - ein Anliegen, das vor allem dem AEW wichtig war. Das geplante Alarmsystem sah eine Einteilung der Umgebung von Kernkraftwerken in zwei verschiedene Gefahrenzonen vor. Zone 1, die einen Radius von circa drei bis vier Kilometern hatte, bildete die größte Gefahrenzone,

\footnotetext{
163 Vgl. dazu Kapitel 4.3.

164 Vgl. CH-BAR\#Е 33 O०C\#1993/155\#647*, Realisierbarkeit von automatischen Alarmsystemen für die Bevölkerung in der Umgebung von Kernkraftwerken, 19.9.1975.

165 CH-BAR\#E819oC\#2003/447\#218*, Besprechung über das Konzept der raschen Alarmierung in der Umgebung von Kernkraftwerken (Protokoll), 26.7.1977.

166 Vgl. dazu Kapitel 3.3.
} 
welche unmittelbar an das betreffende Atomkraftwerk angrenzte. In Zone 2, welche Zone 1 umschloss und ungefähr einen Radius von 20 Kilometern aufwies, herrschte eine mittlere Gefahr. In diesen beiden Gebieten sollte das Alarmsystem zum Einsatz kommen. Zwischen Bund, Kantonen und Kernkraftwerkbetreibern bestand Einigkeit darüber, dass für die Kosten des Alarmsystems grundsätzlich das Verursacherprinzip galt. Dies bedeutete, dass die Kernkraftwerkbetreiber dessen Aufbau - also die notwendigen Sirenen und die Kommunikationsmittel - bezahlen mussten. Die Kernkraftwerkbetreiber und Projektanten akzeptierten auch ohne Weiteres, dass für Zone 1 ein Alarmsystem verwirklicht werden musste und sie dafür aufzukommen hatten. ${ }^{167}$ Der Aufbau des Alarmsystems für Zone 1 gelang in der Folge ohne größere Konflikte termingerecht, sodass eine Alarmierungsmöglichkeit wie geplant ab Anfang des Jahres 1980 bestand. ${ }^{168}$

Bei der Realisierung des Alarmsystems für Zone 2 ergaben sich indessen wie die ASK im August 1978 festhielt - „Unklarheiten“, welche „eine Weiterführung der Arbeiten erschweren“ würden. ${ }^{169}$ Die festgestellten „Unklarheiten“ betrafen in erster Linie Finanzierungsfragen - und damit die Interessen der Kernkraftwerkbetreiber. Bereits anlässlich einer Besprechung mit Vertretern des Alarmausschusses und der ASK im Juni 1977 hatten die Kernkraftwerkbetreiber und Projektanten „einige Bedenken und Einwände zur Grösse und zur geplanten Organisation der Zone 2" geäußert. ${ }^{170}$ Ziel des Alarmausschusses war es nämlich, in Zone 2 die Alarm- und Schutzmaßnahmen für Reaktorunfälle mit denjenigen für Atomexplosionen zu vereinheitlichen. ${ }^{171}$ Diese Pläne stießen bei den Kernkraftwerkbetreibern und Projektanten auf Kritik. Befürchtet wurde, die Errichtung der Zone 2, die auch dem Schutz vor Atombomben dienen sollte, „könnte dazu führen, dass die Kernkraftwerke noch mehr zum Sündenbock werden. Man sollte deutlich sagen, dass die Zone 2 nichts Spezifisches für die Kernkraftwerksumgebung

167 Vgl. CH-BAR\#E819oC\#2003/447\#218*, Besprechung mit der Gruppe der Kernkraftwerksbetreiber und Projektanden, 28.6.1977; CH-BAR\#E819oC\#1993/149\#49*, Aktennotiz betreffend Uebersicht über das Ergebnis des Vernehmlassungsverfahrens betreffend Verordnung über den Notfallschutz in der Umgebung von Kernanlagen, ohne Datum.

168 Vgl. CH-BAR\#E819oC\#1993/149\#49*, Stand der Realisierung des Alarmsystems in den Zonen 1 und 2 der Kernkraftwerke Beznau, Gösgen und Mühleberg, 23.6.1981.

169 CH-BAR\#E439oC\#1997/14\#230*, Stand der Realisierung im August 1978, 7.8.1978.

17 O CH-BAR\#E819oC\#2003/447\#218*, Besprechung mit der Gruppe der Kernkraftwerksbetreiber und Projektanden, 28.6.1977.

171 Nach den Plänen des Alarmausschusses sollte sich Zone 2 künftig sogar auf das Gebiet der ganzen Schweiz erstrecken und dadurch überall eine erhöhte Schutzbereitschaft ermöglichen. 
ist [...]."172 Daraufhin versicherten der Präsident des Alarmausschusses Otto Huber und der Leiter der Sektion für Personen- und Umgebungsschutz der ASK Serge Prêtre, dass man „die Katastrophenplanung nicht auf dem Rücken der Kernkraftwerke austragen“ wolle. Man werde „klar sagen, dass die Vorbereitungen in der Zone 2 nicht nur für Kernkraftwerke, sondern auch für die allgemeine Bedrohung durch radioaktiven Ausfall von Atomwaffen getroffen werden." Zudem würden die Kernkraftwerke in der Zone 2 „nur das bezahlen müssen, was spezifisch für die Schutzmassnahmen bei einem Kernkraftwerksunfall an Kosten anfällt.“173 Diese Position wurde den Kernkraftwerkbetreibern im Juni 1979 seitens des Bundesamtes für Energiewirtschaft (BEW) und des Bundesamtes für Zivilschutz erneut bestätigt. Ferner wurde vereinbart, dass die ASK den Kernkraftwerkbetreibern die einzelnen kantonalen Projekte jeweils vorlegen würde. ${ }^{174}$

Dass diese Sichtweise nicht unbestritten war, zeigte sich bei der Vernehmlassung zur Verordnung über den Notfallschutz in der Umgebung von Kernanlagen. Die Notfallschutzverordnung, welche der Bundesrat schließlich im November 1983 verabschiedete, umschrieb nicht nur die Aufgaben der Betreiber von Atomanlagen, der beteiligten Bundesstellen, der Kantone und Gemeinden, sondern regelte auch die Verteilung der Kosten für die Notfallorganisation und das Alarmsystem. ${ }^{175}$ Dieser Kostenteiler sah unter anderem vor, dass die Kernkraftwerkbetreiber die Kosten für die erste Beschaffung und Installation der Sirenen in den Zonen 1 und 2 sowie für die Fernsteuerung der Sirenen und die benötigten Übermittlungseinrichtungen übernehmen sollten. Die Kantone Luzern, Waadt und Basel-Land forderten nun allerdings, dass die Kernkraftwerkbetreiber auch für den Unterhalt, die Reparaturen und den Ersatz der Alarmmittel in der Zone 2 aufzukommen hätten. Das BEW wies diese Begehren mit der Begründung ab, die Alarmmittel der Zone 2 seien in das Zivilschutzkonzept integriert, würden sich im Besitz der Gemeinden befinden und könnten verschiedenen Zwecken dienen. ${ }^{176}$ Bereits einige Zeit zuvor hatte

\footnotetext{
172 CH-BAR\#E819oC\#2003/447\#218*, Besprechung mit der Gruppe der Kernkraftwerksbetreiber und Projektanden, 28.6.1977.

173 Ebd.

174 Vgl. CH-BAR\#E819oC\#2003/447\#224*, Protokoll der Besprechung über Planung und Realisierung des Alarmsystems in der Zone 2, 8.6.1979.

175 Vgl. CH-BAR\#E819oC\#1993/149\#49*, Verordnung über den Notfallschutz in der Umgebung von Kernanlagen, 28.11.1983. Vgl. auch CH-BAR\#E3300C\#1996/289\#564*, Schreiben des BEW an den Alarmausschuss, das Eidg. Institut für Reaktorforschung, die KSA und die KUeR, 22.5.1981.

176 Vgl. CH-BAR\#E819oC\#1993/149\#49*, Aktennotiz betreffend Uebersicht über das Ergebnis des Vernehmlassungsverfahrens betreffend Verordnung über den Notfallschutz in der Umgebung von Kernanlagen, ohne Datum.
} 
sich die ASK dafür ausgesprochen, dass die öffentliche Hand „zumindest einen symbolischen Beitrag" für die Alarmierungsmittel in der Zone 2 leisten sollte. Zudem seien für die notwendigen Kommunikationsmittel zwischen den kantonalen Katastrophenstäben und den Gemeindestäben Richtlinien zu erlassen, „da ansonst ,vergoldete' Systeme installiert werden und von den

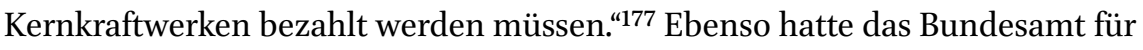
Zivilschutz den betroffenen Kantonen und Gemeinden in einem offiziellen Schreiben empfohlen, „die Kraftwerke beim Aufbau der Sirenenanlagen [...] zu unterstützen“, da diese „auch dem Zivilschutz dienen“ würden. ${ }^{178}$ Der Bund - und hier insbesondere das BEW mit seinen Abteilungen - war bei der Realisierung des raschen Alarmsystems in der Nähe von Atomkraftwerken also sehr darauf bedacht, die finanziellen Interessen der Kernkraftwerkbetreiber im Rahmen des Verursacherprinzips so gut wie möglich zu schützen. Deshalb fanden auch die Forderungen mehrerer Kantone nach einer Veränderung des Kostenteilers zuungunsten der Kernkraftwerke kein Gehör. Politische Rücksichtnahmen von Organen und Behörden des Bundes betrafen also nicht nur die öffentliche Meinung, sondern insbesondere auch das wirtschaftliche Wohl der Kernkraftwerkbetreiber.

\section{Zoneneinteilung oder die Produktion, unsicheren'Wissens}

Das Konzept des raschen Alarmsystems sah ein zweistufiges Alarmsystem vor, das zwischen Warnung und Alarm unterschied (Abb. 25). Eine automatische Warnung erfolgte, wenn sich in einem Kernkraftwerk ein Unfall mit Austritt von Radioaktivität ereignete, aber keine unmittelbare Gefahr des Entweichens radioaktiver Stoffe in die Umgebung bestand. Das Kernkraftwerk sollte die Überwachungszentrale des Alarmausschusses und die für die Zone 1 zuständigen Gemeindebehörden warnen, während die Überwachungszentrale die Warnung der Gemeindebehörden der Zone 2 sowie weiterer Stellen - darunter der Alarmausschuss und die Kantonsbehörden beider Zonen - übernehmen würde. Diese Warnungen wurden nicht an die Bevölkerung weitergegeben. Ziel einer Warnung war es, die Einsatzbereitschaft aller beteiligten Behörden und Organe sicherzustellen. ${ }^{179}$

Ein Kernkraftwerk löste Alarm aus, wenn mit einem Entweichen größerer Mengen radioaktiver Stoffe in die Umgebung zu rechnen war. Das

177 CH-BAR\#E439oC\#1997/14\#230*, Stand der Realisierung im August 1978, 7.8.1978.

178 CH-BAR\#E819oC\#2003/447\#224*, Schreiben von H. Mumenthaler an die Zivilschutzämter der Kantone Aargau, Basel-Land, Bern, Fribourg, Luzern, Solothurn und Zürich, 25.6.1979.

179 Vgl. CH-BAR\#E330oC\#1993/155\#647*, Notfallplanung für die Umgebung von Kernkraftwerken, Mai 1977 . 


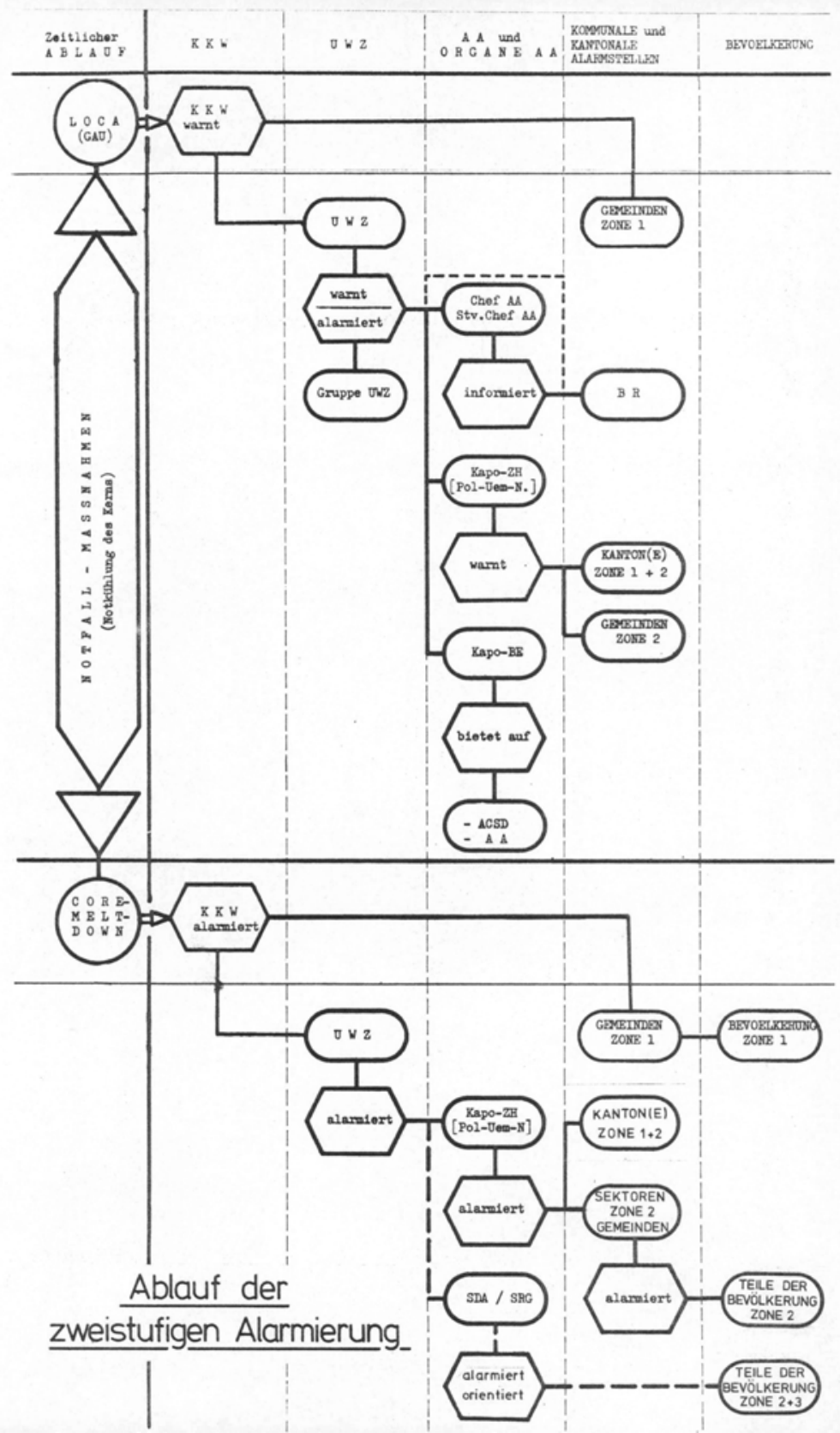

Abb. 25 Ablaufschema der zweistufigen Alarmierung, 1977. 
Kernkraftwerk trug die Verantwortung für die rechtzeitige Alarmierung und musste den Alarm an die Überwachungszentrale und die Behörden der Zone 1 weitergeben. Letztere hatten bei einem Alarm für die betroffene Bevölkerung sofort zweckmäßige Schutzmaßnahmen - etwa Keller und Schutzräume aufsuchen, im Haus bleiben oder Türen und Fenster schließen - anzuordnen. Die Überwachungszentrale würde für die Alarmierung aller zuständigen Behörden in den betroffenen Sektoren der Zone 2 sorgen und diese wiederum sollten die dortige Bevölkerung alarmieren. Ziel des raschen Alarms war es, für die Bevölkerung der Zone 1 und für Teile der Bevölkerung der Zone 2 bei einem atomaren Notfall sofort geeignete Schutzvorkehrungen anordnen zu können. ${ }^{180}$

Dieses zweistufige Alarmsystem für die Umgebung der Kernkraftwerke zeigt, dass die Einteilung der Gebiete um die Kernkraftwerke in zwei Zonen eine große Bedeutung aufwies. Wie kam diese Zoneneinteilung zustande? Ich werde im Folgenden argumentieren, dass die Zoneneinteilung für das rasche Alarmsystem auf ,unsicherem' Wissen basierte. ${ }^{181}$ Mit dem Begriff des ,unsicheren 'Wissens ist gemeint, dass sich probabilistische Annahmen und Plausibilitätsüberlegungen aus unterschiedlichen Wissensfeldern zum einen sowie normative Setzungen zum anderen zu einem Wissen amalgamierten, das zwar Rationalität beanspruchte und Evidenz erzeugte, letztlich aber einen hohen Grad von Kontingenz und Arbitrarität aufwies. ${ }^{182}$

Um die Alarmgebiete und die Schutzmaßnahmen im Rahmen des raschen Alarmsystems zu bestimmen, wurde der sogenannte schwerste theoretisch denkbare Unfall herangezogen. Für dessen Definition stützten sich die ASK und der Alarmausschuss auf eine auch als Rassmussen-Bericht bekannte US-amerikanische Studie aus dem Jahr 1974. Darin wurden die Unfallwahrscheinlichkeiten bei Versagen aller möglichen Reaktorsicherheitssysteme abgeschätzt und für die einzelnen Unfälle die zu erwartende, in die Umgebung freigesetzte Radioaktivitätsmenge berechnet. Für den schwersten theoretisch denkbaren Unfall - Verlust des Kühlmittels, Versagen aller Notkühlsysteme, Bruch der Sicherheitsbehälter - ging die Studie davon aus, dass praktisch alle flüchtigen Spaltprodukte in die Umgebung austreten würden. ${ }^{183}$ Die im Rassmussen-Bericht angenommene und dem raschen Alarmsystem zugrunde

\footnotetext{
18 o Vgl. ebd.

181 Nicht zuletzt aus diesem Grund bildet die nach wie vor bestehende Zoneneinteilung bis heute Gegenstand von Kontroversen.

182 Zum Begriff des ,unsicheren' Wissens v. a.: Spoerhase/Werle/Wild 2009. Vgl. auch Engel/ Halfmann/Schulte 2002.

183 Vgl. CH-BAR\#E330oC\#1993/155\#647*, Notfallplanung für die Umgebung von Kernkraftwerken, Mai 1977 .
} 
gelegte Ausgangslage war Mitte der 1970er Jahre insofern neu, als die bestehenden, von Reaktorherstellern erarbeiteten Sicherheitsberichte nie von einem möglichen Versagen sämtlicher Sicherheitssysteme ausgegangen waren und insofern auch nie die Möglichkeit eines allfälligen Super-GAUs, das heißt eines Unfalls, welcher den GAU, also den größten anzunehmenden Unfall, überstieg, postuliert hatten. ${ }^{184}$

Um für einen Super-GAU unterschiedliche Gefahrenzonen zu definieren, stützten sich die ASK und der Alarmausschuss in erster Linie auf meteorologische Daten und bestimmte Grenzwerte von Strahlen. Aus der Kombination dieser beiden Wissensbestände ergab sich dann die Zoneneinteilung. So umfasste Zone 1 jenes Gebiet, in dem Personen, die sich während der ganzen Durchzugszeit der radioaktiven Wolke im Freien aufhalten würden, eine Dosis von mehr als 100 rem durch die Strahlung aus der Wolke akkumulieren könnten. Um die Zonengrenzen festzulegen, wurde für den definierten schwersten theoretisch denkbaren Unfall die Ausbreitung der radioaktiven Wolke mit allen möglichen Wetterkombinationen durchgerechnet. Der Radius der Zone 1 in einem bestimmten Gebiet ergab sich aus der Annahme von Wetterbedingungen, bei denen die Dosis von 100 rem am weitesten vom Kernkraftwerk entfernt erreicht würde. Zone 2 wiederum schloss an Zone 1 an und war auf einen äußeren Radius von 20 Kilometern begrenzt. Die radioaktive Wolke würde in dieser Zone nur die in der Windrichtung liegenden Sektoren kontaminieren, wobei die beim Durchgang der Wolke an einem Ort akkumulierte Dosis unterhalb von 100 rem liegen würde. Der Radius des Kreises der Zone 2 ergab sich aus der mittleren Windgeschwindigkeit und einem Zeitlimit von zwei Stunden. ${ }^{185}$ Um bei einem atomaren Unfall aktuelle und exakte Wetterdaten aus dem Gebiet des betroffenen Kernkraftwerkes zu erhalten, mussten die Atomkraftwerke auf ihrem Gelände einen sogenannten Meteomast aufstellen und die Daten dieser meteorologischen Messungen automatisch an die Überwachungszentrale des Alarmausschusses übermitteln. ${ }^{186}$

Das Zeitlimit von zwei Stunden und der Grenzwert von 100 rem beruhten auf willkürlich gesetzten Annahmen. Was die zwei Stunden betraf, so wurde erwartet, dass diese Zeitdauer für die Alarmierung von Behörden und Bevölkerung in der Zone 2 ausreichen müsste. Der Grenzwert von 100 rem wiederum bildete diejenige Größe, von der Strahlenschützer annahmen, dass

184 Vgl. CH-BAR\#E330oC\#1993/155\#594*, Hypothesen für die Berechnung der Radioaktivitätsfreisetzung bei schweren Reaktorunfällen, 20.11.1974.

185 Vgl. CH-BAR\#E330oC\#1993/155\#647*, Notfallplanung für die Umgebung von Kernkraftwerken, Mai 1977 .

186 Vgl. CH-BAR\#E819oC\#1993/149\#49*, Stand der Realisierung des Alarmsystems in den Zonen 1 und 2 der Kernkraftwerke Beznau, Gösgen und Mühleberg, 23.6.1981. 


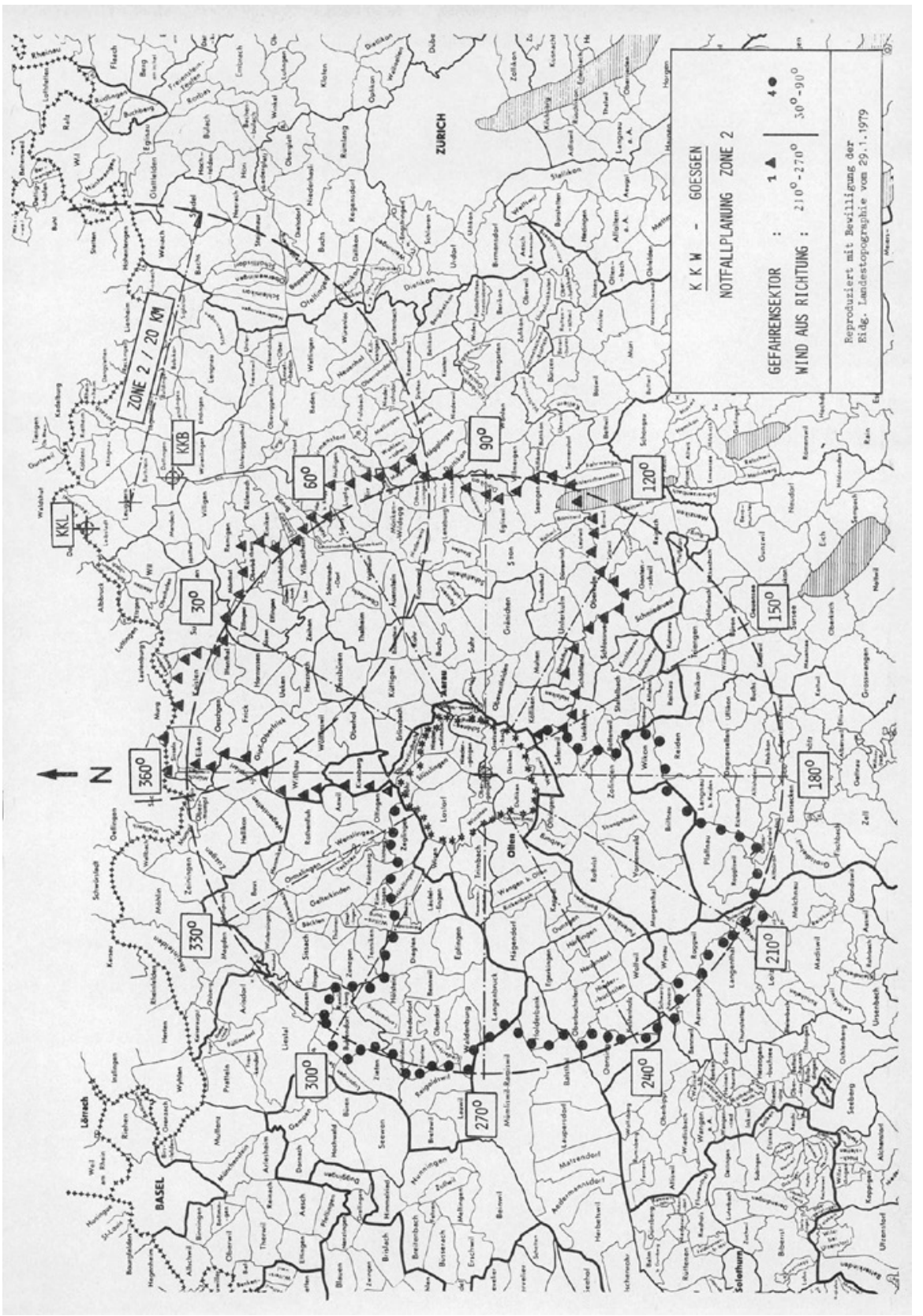

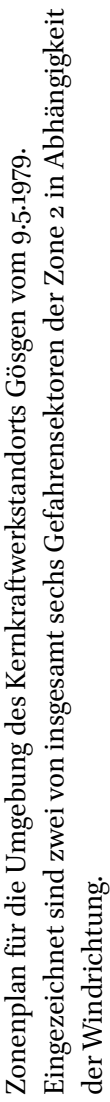

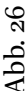


sie überschreitende Werte zu Strahlenkrankheit führen würden, darunterliegende Werte indessen noch nicht (was hingegen nicht bedeutete, dass Dosen unter 100 rem nicht gesundheitsschädigend sein könnten). ${ }^{187}$ Dass es sich bei den 100 rem um eine weitgehend arbiträre Festsetzung handelte, lässt sich einem Papier entnehmen, das von der Sektion für Personen- und Umgebungsschutz der ASK verfasst wurde. Dort heißt es, die Beschränkung des Alarmgebietes von Zone 1 auf Gebiete mit Dosen von mehr als 100 rem trage „der kleinen Eintretenswahrscheinlichkeit von schweren Reaktorunfällen Rechnung “. ${ }^{188}$ Die Sektion für Personen- und Umgebungsschutz gab somit indirekt $\mathrm{zu}$, dass es nicht nur medizinische Überlegungen, sondern auch probabilistische Annahmen waren, aufgrund welcher der Grenzwert auf hohe 100 rem festgelegt wurde. Offensichtlich ging es darum, die Zone 1, in welcher die Kernkraftwerke ein rasches Alarmsystem installieren mussten, nicht zu groß zu konzipieren.

Studiert man die vorhandenen Dokumente zur Zoneneinteilung, so wird deutlich, dass für deren Festlegung neben Wetterbedingung und Toleranzwert noch ein drittes Kriterium ausschlaggebend war: die Bevölkerungsdichte. Der Faktor der Bevölkerungsdichte wirkte sich direkt auf die Festlegung der Gefahrenzonen aus. Dies zeigt sich etwa anhand der Definition des Alarmgebietes für die Grenzdosis von 100 rem, also für Zone 1. Für jeden Sektor dieser Zone ließen sich verschiedene Windgeschwindigkeiten mit entsprechenden Häufigkeiten ermitteln, woraus wiederum verschiedene Grenzdistanzen resultierten. ${ }^{189}$ Die ASK hielt dazu in einer internen Studie fest: „Ein maximales Alarmgebiet, das aus den jeweiligen maximalen Distanzen in den einzelnen Sektoren besteht, würde einer konservativen Betrachtungsweise entsprechen. Dagegen entspräche ein Alarmgebiet, bestehend aus Distanzen, die sich aus den grössten Windfrequenzen in den jeweiligen Sektoren ergeben, einer pragmatischen Betrachtungsweise. ${ }^{“ 190}$ Die ASK schlug nun vor, die „Betrachtungsweise“ nach Siedlungsdichte auszuwählen: „Für Sektoren, die eine hohe Bevölkerungsdichte aufweisen, soll eher eine grössere Distanz gewählt werden, während in den restlichen Sektoren die Auswahl der Grenzdistanz nach der pragmatischen Betrachtungsweise angebrachter wäre. ${ }^{191}$ Für dicht

\footnotetext{
187 Vgl. CH-BAR\#E330oC\#1993/155\#647*, Notfallplanung für die Umgebung von Kernkraftwerken, Mai 1977 .

188 CH-BAR\#E819oC\#2003/447\#218*, Darlegung betreffend Automatisches Alarmsystem für die Bevölkerung in der Umgebung von Kernkraftwerken, 29.9.1976.

189 Vgl. CH-BAR\#E330oC\#1993/155\#647*, Realisierbarkeit von automatischen Alarmsystemen für die Bevölkerung in der Umgebung von Kernkraftwerken, 28.5.1976.

190 Ebd.

191 Ebd.
} 
besiedelte Gebiete waren also prinzipiell größere Schutzradien vorgesehen als für dünn besiedelte Gegenden.

Neben dem 100 rem-Grenzwert diskutierte die ASK als mögliches Kriterium für die Festlegung der Zone 1 auch die Anzahl der potenziellen akuten StrahlenTodesfälle. Die Anzahl der Todesfälle in einem bestimmten Sektorsegment ließ sich dabei durch die Bildung von Produkten aus der Bevölkerungszahl und der Wahrscheinlichkeit für akuten Strahlentod bei entsprechender Dosis berechnen. ${ }^{192}$ Das Kernkraftwerk Gösgen schnitt dabei im schweizerischen Vergleich besonders schlecht ab, weil sich in dessen Umgebung die bevölkerungsreichen Gebiete Aarau und Olten befinden. ${ }^{193}$ Aus der Berechnung der Strahlen-Todesfälle ergaben sich auch gouvernementale Steuerungsfantasien. So dachte Serge Prêtre, Leiter der Sektion für Personen- und Umgebungsschutz der ASK, in einem vertraulichen Papier darüber nach, „dass man die Unfallfolgen soweit möglich so ,steuern' sollte, dass gewisse Sektoren unbedingt geschont bleiben. Eine gute Abgabe-Strategie könnte das Ausmass des Unfalls wesentlich vermindern. ${ }^{194}$ Durch ein "[g]esteuertes Abblasen“ sollten bei einem atomaren Unfall also die Opferzahlen gesenkt werden, indem die radioaktive Wolke bei entsprechenden Wetter- und Windverhältnissen auf dünn besiedeltes Gebiet gelenkt würde. Aus diesen Lenkungsvisionen ergaben sich für Prêtre auch Postulate hinsichtlich der Bevölkerungsentwicklung: „Für Sektoren, wo die Anzahl potentieller Todesfälle gross ist (z.B. > 1'ooo), sollte man über rechtliche Mittel verfügen, um den Bevölkerungszuwachs (inkl. auch zeitlich grosse Menschenanhäufung wie in Schwimmbädern) zu stoppen. Das ist ein sehr heisses Eisen, das man einmal mutig anpacken sollte. ${ }^{195}$ Innerhalb der ASK wurde in der Folge diskutiert, ob die Anzahl der Strahlen-Todesfälle für künftige Kernkraftwerke nicht als Standortbewertungsgröße herangezogen werden könnte. ${ }^{196}$ Diese Diskussion erübrigte sich insofern, als zu diesem Zeitpunkt Mitte der 1970er Jahre bereits alle in der Schweiz je realisierten Kernkraftwerke eine Standortbewilligung besaßen. Grundsätzlich lässt sich ab Mitte der 1970er Jahre indessen eine Entwicklung dahingehend feststellen, dass die demografischen Verhältnisse an einem Kernkraftwerkstandort nicht mehr einfach simpel aufgerechnet wurden - etwa indem die kumulative

\footnotetext{
192 Vgl. ebd., Berechnung der potentiellen akuten Strahlen-Todesfälle in der Umgebung eines KKW nach einem äusserst schweren Kernreaktorunfall, 23.7.1976.

193 Vgl. ebd., und Berechnung der Anzahl potentieller akuter Strahlen-Todesfälle in der Umgebung der Kernkraftwerke Leibstadt und Mühleberg als Folge eines äusserst schweren Kernreaktorunfalles, 20.8.1976.

194 Ebd., Mögliche Konsequenzen aus dieser Studie (Anhang), ohne Datum.

195 Ebd.

196 Vgl. ebd.
} 
Bevölkerungsverteilung oder die kumulative Bevölkerungsdichte ermittelt wurde -, sondern differenzierteren Risikoberechnungen Platz machten. Diese gewichteten - wie dies etwa der sogenannte Site Population Factor tat - die Strahlenrisiken der in der Nähe von Kernkraftwerken lebenden Bevölkerung in Abhängigkeit verschiedener Faktoren (beispielsweise der Distanz und der meteorologischen Verhältnisse) unterschiedlich. ${ }^{197}$

Auch politische Faktoren wie Staats-, Kantons- und Gemeindegrenzen spielten bei der Festlegung der Gefahrenzonen eine Rolle. So wurden die Zonengrenzen der Zone 2 mit einem Radius von ungefähr zwanzig Kilometern jeweils mit den Grenzen der dortigen Gemeinden in Übereinstimmung gebracht. Um dies zu erreichen, wurden Gemeinden, bei denen sich nur kleinere Wohngebiete noch in der 2o-Kilometer-Zone befanden, als Ganzes aus der Zone 2 ausgeschieden, während Gemeinden, die ebenfalls nur teilweise in dieser Zone lagen, jedoch mit erheblichen Wohngebieten, als Ganzes der Zone 2 zugeordnet wurden. Ebenso wurden im Südosten der Kernkraftwerke Beznau einige Gemeinden aus der Zone 2 ausgeschlossen, nachdem für die beiden sehr nahe beieinanderliegenden Atomkraftwerkstandorte Beznau und Leibstadt eine gemeinsame Zone 2 festgelegt worden war. ${ }^{198}$ Die Berner Kraftwerke AG wiederum schlug im Juni 1979 anlässlich einer Besprechung mit kantonalen Behörden und Vertretern der ASK und des BEW hinsichtlich des Alarmgebietes des Kernkraftwerks Mühleberg vor, „die Zone II auf einen Radius von 17,4 km [zu] beschränken, um die Kantone SO [Solothurn] und NE [Neuenburg], sowie VD [Waadt] ausser der Gde [Gemeinde] Faoug auszuklammern. ${ }^{199}$ Es ist plausibel anzunehmen, dass die gewünschte Verkleinerung der Zone 2 von 20 auf etwas mehr als 17 Kilometer das Ziel verfolgte, die Berner Notfallplanung zu vereinfachen, indem so die Koordination mit Nachbarkantonen auf ein Minimum reduziert würde. Koordination bezüglich des Notfallmanagements bildete indessen nicht nur zwischen verschiedenen Kantonen, sondern auch zwischen der Schweiz und ihren Nachbarstaaten eine Herausforderung. So stellte sich bei denjenigen Schweizer Kernkraftwerken, die sich in Grenznähe befanden - Beznau I und II und Leibstadt - das Problem, dass ein Teil der Gefahrenzonen auf bundesdeutsches Gebiet fiel. Im Prinzip brach das Alarmgebiet dort an der Grenze jeweils einfach ab. Allerdings schloss die Schweiz 1978 mit der Bundesrepublik Deutschland (sowie später auch mit Frankreich

197 Vgl. CH-BAR\#E819oC\#2003/447\#224*, Site Population Factor (SPF) als Standortbewertungskriterium, 8.9.1978.

198 Vgl. ebd., Planung und Realisierung des Alarmsystems in der Zone 2, 13.3.1979.

199 Ebd., Aktennotiz betreffend Besprechung mit Vertretern von Kanton Bern und Gemeinden über die Notfallplanung KKW Mühleberg, 18.6.1979. 
und mit Italien) Staatsverträge über den radiologischen Notfallschutz ab, welche die gegenseitige Warnung und Alarmierung bei atomaren Notfällen regelten. ${ }^{200}$ Auch heute ist es noch so, dass politische Grenzen als Grenzen der Gefahrenzonen in der Umgebung von Kernkraftwerken fungieren. So folgen die Zonen- und Sektorengrenzen der aktuellen Zoneneinteilung den Gemeindegrenzen. ${ }^{201}$

Die Einteilung der Nahzonen von Kernkraftwerken im Rahmen des raschen Alarmsystems stellte ein Präventionssystem dar, das Opfer in Kauf nahm. Um diese potenziellen Opfer auf die Bevölkerung zu verteilen, wurden bei der Risikofestlegung bisweilen problematische Bewertungen vorgenommen. Der normative Faktor der Siedlungsdichte spielte dabei eine zentrale Rolle: So waren für dicht besiedelte Gebiete mitunter größere Schutzgebiete vorgesehen als für dünn besiedelte. Wie gezeigt, bildeten auch politische Grenzen Kriterien für die Zoneneinteilung. Die für die Definition der Gefahrenzonen verantwortlichen Wissenschaftler wiesen selbst darauf hin, dass die Festlegung der Radien von Schutzzonen und entsprechende Schutzmaßnahmen weniger eine wissenschaftliche, als vielmehr eine politische Frage darstellen würde. So hielt etwa ein internes Papier der ASK fest:

Der Aufwand, der beim Aufbau einer solchen „dritten Barriere“ [gemeint ist das rasche Alarmsystem] getrieben werden muss oder soll, hängt nicht unwesentlich von politischen Faktoren ab. Gerade hier konnte aber im Gedankenaustausch mit Politikern des Kantons Aargau festgestellt werden, dass diese Politiker ein Alarmsystem $[\ldots]$ befürworten $[\ldots] .{ }^{202}$

Was als ein akzeptables Risiko galt und welche Alarm- und Schutzmaßnahmen dafür als notwendig erachtet wurden, hatte somit nicht die Wissenschaft, sondern die Politik zu entscheiden.

Der Wissenschaftssoziologe Peter Weingart hat am Beispiel der Kernenergie zu Recht darauf hingewiesen, dass die Sicherheitsvorkehrungen für derart komplexe Technologien den von diesen ausgehenden Risiken konstitutiv hinterherhinken, weil sich diese Technologien immer an der Forschungsfront bewegen und potenzielle Gefahren erst im Prozess von deren Entwicklung überhaupt sichtbar werden. Die Wissenschaft kann die Sicherheitserwartungen der Politik an bestimmte technische Systeme folglich immer erst im Nachhinein

200 Vgl. die entsprechenden Akten in: CH-BAR\#E2001E-o1\#1987/78\#614*, CH-BAR\#E330oC \#1993/157\#46o* und CH-BAR\#E439oC\#1997/14\#523*.

201 Vgl. Kernkraftwerke: Zonen (Webseite).

202 CH-BAR\#E819oC\#2003/447\#218*, Darlegung betreffend Automatisches Alarmsystem für die Bevölkerung in der Umgebung von Kernkraftwerken, 29.9.1976. 
erfüllen - und diese damit legitimieren. ${ }^{203}$ Diese Beobachtung ist sicherlich richtig - sie lässt indessen außer Acht, dass normativ-politische Kriterien (implizit oder explizit) auch in die wissenschaftlichen Berechnungen, Konzepte und Studien einfließen. Die Politik formuliert somit nicht nur Sicherheitserwartungen, auf welche die Wissenschaft (zustimmend oder ablehnend) antwortet. Vielmehr prägen politische Faktoren die wissenschaftliche Erforschung und Festlegung möglicher Risiken permanent mit.

\subsection{Fazit}

Das Alarmierungsdispositiv bildete ein konstitutives Element der Sicherheitsdispositive gegen Strahlen und stellte insofern einen zentralen Bestandteil der Präventionsregime des schweizerischen Kalten Krieges dar. Der Alarmierungsprozess war dabei sowohl technisch als auch konzeptionell und organisatorisch sehr voraussetzungsreich: Die permanente preparedness konnte schon bei der Alarmierung scheitern. Als prekär erwiesen sich insbesondere die vielfältigen Informations- und Kommunikations-, Transformations- und Übersetzungsprozesse, ohne welche das Alarmierungsdispositiv nicht reibungslos funktionierte. Hier offenbarten sich beim praktischen Aufbau der Alarmorganisation immer wieder Probleme bei der Umsetzung der Anforderungen der ,koordinierten Sicherheit".

Ein wesentliches Handicap bildete dabei der Umstand, dass militärische Infrastrukturen nur im Aktivdienstfall vollumfänglich zur Verfügung standen, dann aber von der Armee beansprucht wurden, und zivile Stellen gleichzeitig gerade im Mobilmachungs- bzw. Kriegsfall nicht mehr richtig funktionsfähig und zudem ressourcenmäßig häufig schlechter ausgerüstet waren als das Militär. Das gemäß dem Konzept der Gesamtverteidigung verlangte Zusammenspiel ziviler und militärischer Teile wies somit konstitutive, inhärente Konstruktionsschwächen auf, die auf eine strukturelle Dysfunktionalität des schweizerischen Gesamtverteidigungssystems hinweisen. So führte der Anspruch, mit denselben personellen und materiellen Mitteln eine Alarmorganisation zu schaffen, die sowohl im Friedens- als auch im Kriegsfall einsatzfähig sein sollte, zu Konflikten und Doppelungen, institutionellen Schlaufen und rechtlichen Unsicherheiten. Dies zeigt sich insbesondere bei der problembehafteten institutionellen Verankerung des Alarmausschusses für den Fall erhöhter Radioaktivität, die mit offenen Koordinationsfragen

203 Vgl. Weingart 2001, S. 156. 
einherging, welche zahlreiche Arbeits- und Studiengruppen über viele Jahre nicht zu beantworten imstande waren.

Am Beispiel des Atomalarms und der Vorbereitung von Strahlenschutzmaßnahmen lässt sich gleichzeitig die Expansionslogik der schweizerischen Gesamtverteidigung während des Kalten Krieges verdeutlichen. Der eidgenössische Notfallföderalismus verlangte nicht nur nach einer Mobilisierung und Integration aller föderalen Ebenen, sondern band auch freiwilliges Milizpersonal, öffentliche Dienste und private Unternehmen in das Alarmierungsdispositiv ein. Dieser expansive Charakter der Alarmorganisation lag auch darin begründet, dass in den 1970er Jahren eine Ausweitung der wahrgenommenen nuklearen Bedrohung auf zivile atomare Katastrophen stattfand. In den Planungen der Alarmorganisation verschränkten sich zivile und militärische Handlungslogiken und Ressourcen und die Grenzen zwischen Friedens- und Kriegszustand verschwammen zusehends. So sollte das Alarmierungsdispositiv nun nicht mehr nur für einen künftigen Atomkrieg, sondern insbesondere auch für mögliche Katastrophen im nuklearen Alltag Alarm- und Schutzmöglichkeiten bieten.

Daraus resultierte die Forderung nach einem spezifischen Alarmsystem in der Umgebung von Atomkraftwerken. Einerseits nahmen die zuständigen Behörden des Bundes, allen voran das Bundesamt für Energiewirtschaft, bei dessen Schaffung Rücksicht auf die finanziellen Interessen der Kernkraftwerkbetreiber, die sich an den Kosten beteiligen mussten. Andererseits basierte die Festlegung der beiden unterschiedlichen Gefahrenzonen des raschen Alarmsystems auf ,unsicherem' Wissen. So war die Zoneneinteilung zwar von wissenschaftlich-medizinischen Kriterien beeinflusst, aber auch von politischen Faktoren und relativ willkürlich gesetzten Annahmen. Gleichzeitig fand vor dem Hintergrund der anhaltenden gesellschaftlichen Debatte über die zivile Nutzung der Atomenergie behördlicherseits ein Lernprozess statt, was die Kommunikation gegenüber der Bevölkerung anbelangte.

Der Aufbau der Alarmorganisation sowie insbesondere des raschen Alarmsystems für Kernkraftwerke zeigt, dass der Umbau der Gesamtverteidigung auf die Katastrophenhilfe bereits in den 1970er und nicht (wie bisher angenommen) erst in den 1980er Jahren einsetzte. Das neue Bedrohungsbild des zivilen atomaren Notfalls stellte dabei den Ausgangspunkt für die Hinwendung des Bevölkerungsschutzes auf zivile Katastrophenereignisse dar. Strahlen bildeten folglich nicht nur im militärischen, sondern auch im zivilen Bereich die Leitbedrohung des schweizerischen Kalten Krieges. 